\title{
ANÁLISIS DE LOS CONJUNTOS LÍTICOS DEL SITIO MULTICOMPONENTE ZOKO ANDI 1. APORTES AL CONOCIMIENTO DE LA TECNOLOGÍA DEL CURSO INFERIOR DEL RÍO COLORADO (PROVINCIA DE BUENOS AIRES, ARGENTINA)
}

\author{
ANALYSIS OF THE LITHIC ASSEMBLAGES IN ZOKO ANDI 1 MULTI-COMPONENT \\ SITE. CONTRIBUTIONS TO THE KNOWLEDGE OF THE TECHNOLOGY OF \\ THE LOWER BASIN OF THE COLORADO RIVER (BUENOS AIRES PROVINCE, \\ ARGENTINA
}

Florencia Santos Valero ${ }^{1,2}$

\begin{abstract}
El siguiente trabajo presenta el estudio tecnológico de los conjuntos líticos del sitio Zoko Andi 1 a lo largo de su ocupación durante el Holoceno Tardío inicial (ca. 1500-1300 años AP) y final (ca. 800-400 años AP). A partir del análisis tecnomorfológico de estos artefactos y de las cadenas operativas de producción se abordó la gestión de rocas en cada uno de los lapsos temporales, estableciendo diferencias y similitudes entre ellos. De esta manera, la información generada contribuyó a ampliar el conocimiento sobre la producción de artefactos líticos durante todo el Holoceno Tardío. Los resultados obtenidos fueron a su vez integrados a otras líneas de evidencia, aportando información acerca de la funcionalidad del sitio y de los patrones de asentamiento de los grupos que lo ocuparon.
\end{abstract}

Palabras claves: Holoceno Tardío, Transición pampeano-patagónica oriental, cadenas operativas.

This paper presents a technological study of lithic assemblages of the Zoko Andi 1 site during its occupation between the Initial Late Holocene (ca. 1500-1300 years BP) and the Final Late Holocene (ca. 800-400 years BP). The management of rocks in each temporal lapse, as well as the differences and similarities between the temporal lapses, was addressed on the basis of a technomorphological and technological (operational chains) analysis. In this way, the information generated contributed to broaden the knowledge about the production of lithic artifacts throughout the Late Holocene. The results were also integrated to other lines of evidence, contributing with information on the functionality of the site and settlement strategies of the occupying groups.

Key words: Late Holocene, Eastern Pampean-Patagonian transition, operational chains.

El sitio Zoko Andi 1 (en adelante ZA 1) se ubica sobre la margen derecha del curso inferior del Río Colorado (en adelante CIRC; partido Villarino, provincia Buenos Aires), en un ambiente ecotonalárido-semiárido, que abarca la transición oriental entre las regiones pampeana y patagónica (Martínez 2017; Martínez et al. 2014; Figura 1 A). La cronología radiocarbónica del sitio permitió establecer un componente arqueológico asociado con el Holoceno Tardío inicial (ca. 1500-1300 años AP) y otro correspondiente al Holoceno Tardío final (ca. 800-400 años AP; Martínez 2017). Si bien los sitios registrados hasta el momento en el CIRC indican la presencia de grupos cazadores-recolectores a lo largo del Holoceno Medio y Tardío, ZA 1 cobra relevancia dado que se trata del único sitio del área de estudio donde se registraron en estratigrafía dos componentes arqueológicos bien diferenciados y para los cuales pudieron obtenerse dataciones absolutas.

En este trabajo se presenta el estudio de los materiales líticos del sitioZA 1 desde una perspectiva temporal, con el objetivo principal de evaluar las diferencias y similitudes entre los conjuntos de cada componente arqueológico. Este análisis abordará la caracterización tecnomorfológica de los artefactos y el estudio de las cadenas operativas, haciendo énfasis en las etapas de producción de soportes y confección del instrumental. A su vez, los resultados obtenidos se discutirán brevemente en relación con las principales

\footnotetext{
${ }^{1}$ Instituto de Investigaciones Arqueológicas y Paleontológicas del Cuaternario Pampeano-Consejo Nacional de Investigaciones Científicas y Técnicas (UE-INCUAPA-CONICET). Olavarría, Buenos Aires, Argentina.

${ }^{2}$ Facultad de Ciencias Sociales, Universidad Nacional del Centro de la Provincia de Buenos Aires. Olavarría, Buenos Aires, Argentina. fsantosvalero@gmail.com
}

Recibido: septiembre 2019. Aceptado: junio 2020. 

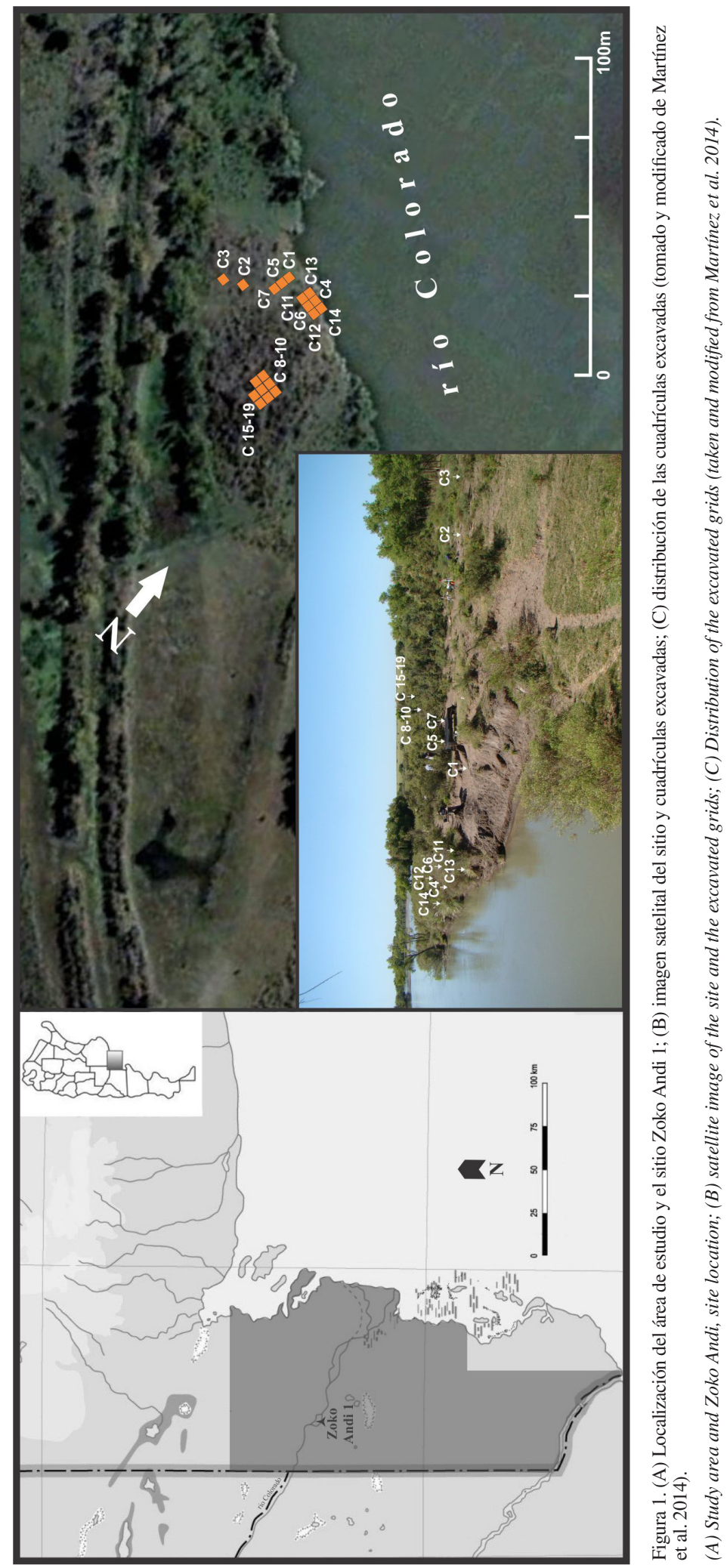
tendencias tecnológicas establecidas para cada momento del Holoceno Tardío en el área de estudio (Armentano 2012; Santos Valero 2015, 2017). Finalmente, a los efectos de abordar aspectos de la funcionalidad del sitio, esta información se integrará a la generada desde otras líneas de evidencia (Alcaráz 2017; Borges Vaz 2019; Martínez y Flensborg 2015; Martínez et al. 2014; Stoessel et al. 2016).

\section{Características Generales del Sitio}

Los trabajos de campo en el ZA 1 implicaron la excavación de 19 cuadrículas de un $\mathrm{m}^{2}$ a lo largo de sucesivas campañas (Figura 1B y C). Los materiales recuperados (principalmente en estratigrafía y, en menor medida, en superficie) incluyen gran cantidad de restos faunísticos, cerámicos, bioarqueológicos, líticos y adornos personales (Alcaráz 2017; Borges Vaz 2019; Flensborg 2017; Martínez y Flensborg 2015; Stoessel et al. 2016). El estudio de la secuencia estratigráfica del sitio permitió identificar seis unidades aloestratigráficas y edafoestratigráficas (Figura 2; Martínez et al. 2014). Las Unidades 6 y 5 son de origen fluvial, mientras que la 4 a 1 son de génesis eólica (Figura 2). La Unidad 6 se corresponde con un meandro abandonado. La Unidad 5 muestra en su parte cuspidal una discordancia que marca la culminación de la depositación de los sedimentos fluviales y el inicio de los eólicos (Figura 2). Dentro de este último conjunto, las unidades 4,3 y 2 b son el resultado de procesos de sedimentación rápida, que finalizan con un suelo enterrado (Unidad 2a), señalando condiciones de mayor estabilidad. Por encima de este paleosuelo, se registró otra discordancia a partir de la cual se observan sedimentos eólicos (Unidad 1) que rematan en el suelo actual.

La cronología de ocupación del sitio se estableció mediante 10 fechados radiocarbónicos (nueve de ellos por AMS y uno estándar). De estos, cuatro fueron realizados sobre huesos de guanaco (Lama guanicoe) con fractura helicoidal, tres sobre fragmentos de carbón, dos sobre restos óseos humanos (Homo sapiens) y el restante sobre un fragmento de cráneo de Ceratophys sp (Martínez 2017;

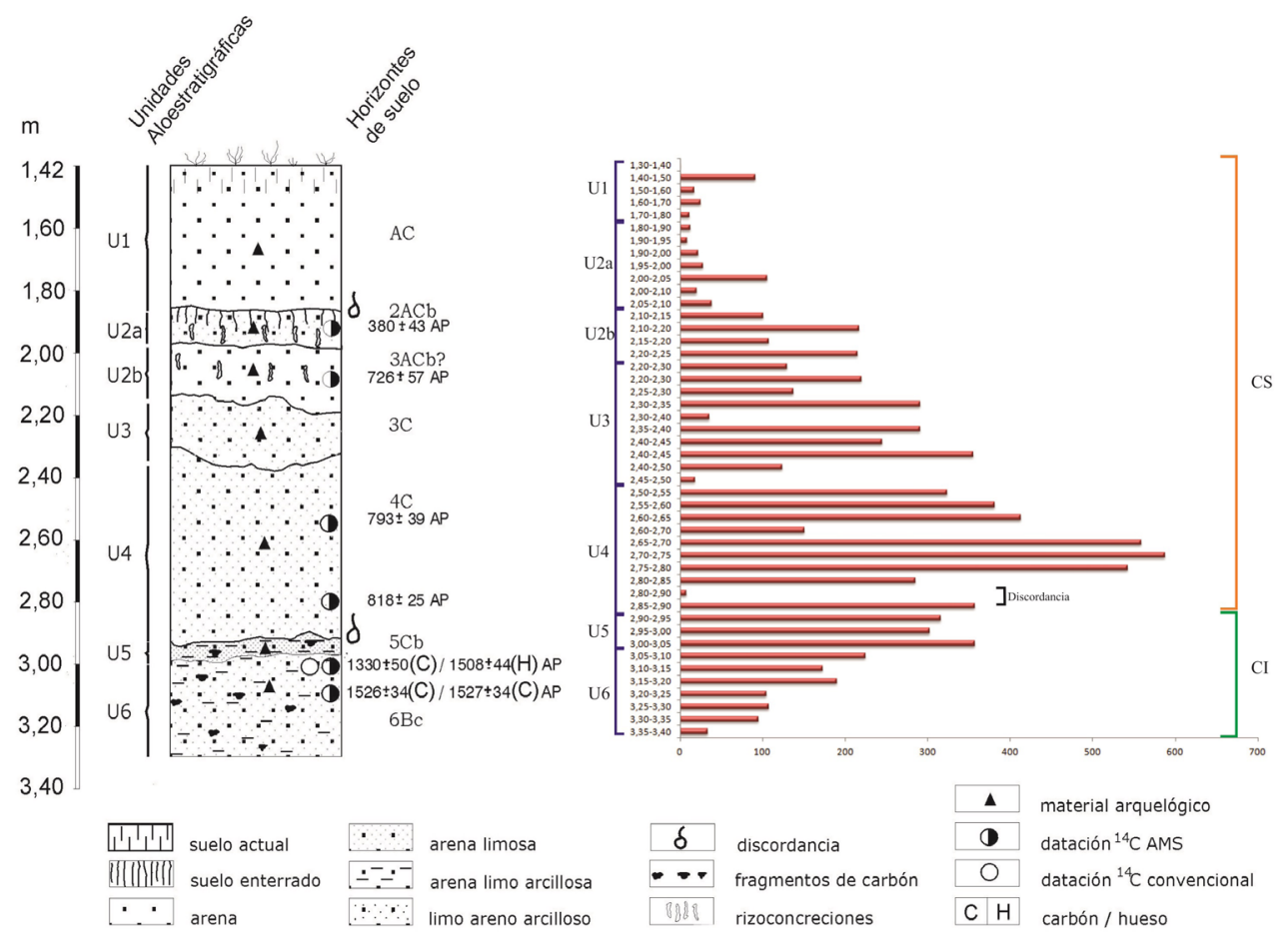

Figura 2. Secuencia estratigráfica de la Cuadrícula 11 (tomado de Martínez 2017) y cantidad de artefactos recuperados por nivel. Stratigraphic sequence of Grid 11 (taken from Martínez 2017) and number of artifacts recovered in each level. 
Martínez et al. 2014). A partir de estos fechados se asignó a las Unidades 6 y 5 una cronología de ca. 1500-1300 años AP, que corresponde al lapso inicial del Holoceno Tardío (Componente Inferior del sitio, en adelante ZA 1 CI). Las unidades superiores (4 a 1) fueron fechadas entre ca. 800-400 años AP y se ubican cronológicamente en el Holoceno tardío final (Componente Superior del sitio, en adelante ZA 1 CS; Figura 2).

El análisis del registro arqueofaunístico (Alcaráz 2017; Stoessel et al. 2016) estableció que durante ambos lapsos del Holoceno Tardío la especie más explotada fue el guanaco, presentando evidencias de intensificación en su consumo (i.e., alto grado de fracturación del conjunto y elevada frecuencia de desechos de fractura; Stoessel et al. 2016). Otras especies consumidas fueron el venado de las pampas (Ozotoceros bezoarticus), ñandú (Rhea americana), roedores, armadillos y aves. A su vez, el análisis del conjunto de fauna mayor permitió reconocer también la presencia de instrumentos óseos confeccionados sobre huesos de guanaco (Stoessel et al. 2016, 2020).

Con respecto al registro bioarqueológico, se identificaron en la parte superior de la duna dos inhumaciones secundarias asociadas a tiestos cerámicos, materiales de molienda y restos faunísticos (Cuadrículas 8 y 9, Figura 1B y C). El Entierro 1 es un enterramiento secundario simple de un individuo masculino adulto, donde solo los huesos de los miembros superiores se encuentran en posición anatómica, algunos de ellos presentando tinciones rojizas. El Entierro 2 se corresponde con una “disposición" (sensu Berón et al. 2002), y está compuesta por unidades anatómicas pertenecientes a un individuo masculino adulto. Se registró la presencia de tinciones rojizas sobre los huesos y dos tembetás óseos asociados a la mandíbula del individuo. Sumado a ello se recuperaron cerca de 100 restos óseos humanos dispersos en la planta de excavación, cuya correspondencia anatómica con los entierros antes mencionados está bajo estudio (Martínez y Flensborg 2015). En base a la disposición de los restos óseos, el nivel de articulación de partes anatómicas en los entierros y la presencia de marcas de corte en algunos huesos, se infiere un intenso proceso de manipulación de cadáveres (Martínez y Flensborg 2015).

En relación con la tecnología cerámica, la presencia de masas de arcillas crudas y cocidas en ambos componentes arqueológicos, indica la elaboración in situ de vasijas con materias primas locales. En los dos bloques temporales, la confección se llevó a cabo mediante la superposición de rollos, resultando en piezas de contornos simples correspondientes a formas globulares y/o subglobulares y superficies alisadas (Borges Vaz 2019). La decoración de las piezas, sin embargo, es diferente en cada momento. En el Holoceno Tardío inicial se distinguen líneas incisas rectas paralelas y en zigzag, así como impresiones mediante un objeto dentado y en un caso por unguiculado. Este último, de acuerdo a los resultados de análisis petrográficos, se trataría de ejemplar foráneo. En tanto hacia la parte final de este periodo se distinguen diseños compuestos por líneas dispuestas en diagonal que forman una trama y figuras rellenas con líneas paralelas (Borges Vaz 2019).

Finalmente, se llevó a cabo el análisis tecnomorfológico de cuentas, tembetás y pendientes recuperados en la excavación (Flensborg 2017). En el componente asociado al Holoceno Tardío inicial se registró gran cantidad de cuentas sobre valvas, dos cuentas líticas, cuatro pendientes, dos tembetás confeccionados sobre hueso (Entierro 2 descrito anteriormente) y un artefacto de valva pulido y de morfología rectangular, considerado una preforma de un tembetá. Asociada al registro del Holoceno Tardío final, se registró la presencia de cuentas de valvas y de un objeto circular intensamente pulido, de una roca indeterminada, que no pudo ser adjudicado a ninguna categoría tecnomorfológica (Flensborg 2017).

La evidencia anteriormente expuesta permitió interpretar a ZA 1 como un lugar elegido para el establecimiento de bases residenciales de actividades múltiples, intensamente ocupado a lo largo del Holoceno Tardío(Martínez2017).Lapresencia de entierros humanos en algunos sectores del médano, la vasta evidencia del consumo de diferentes especies de fauna menor y mayor, así como el registro de diferentes momentos en la confección de vasijas cerámicas son algunas de las líneas de análisis que apoyan esta propuesta y permiten establecer el desarrollo tanto de actividades domésticas como inhumatorias (Alcaráz 2017; Borges Vaz 2019; Martínez 2017; Martínez y Flensborg 2015; Martínez et al. 2014; Stoessel et al. 2016).

\section{Antecedentes en el Estudio de la Tecnología Lítica del CIRC}

El análisis de la gestión de rocas de diferentes conjuntos artefactuales (Armentano 2012; Santos Valero 2015, 2017) permitió establecer el empleo mayoritario de rocas areales (ver Muestra y Metodología) a lo largo de toda la ocupación del área, la cual abarca el Holoceno Medio (ca. 6300-4100 años AP), el Holoceno Tardío inicial (ca. 3000-1000 años AP) y Holoceno Tardío final (ca. 1000-250 años AP; Martínez 2017). Sin embargo, a través del tiempo se observan diferencias en cuanto a sus lugares de aprovisionamiento (costa atlántica y/o interior del área de estudio), las litologías elegidas y los tamaños seleccionados. En este sentido, las materias primas que presentan las frecuencias más altas durante el Holoceno Medio y Tardío inicial son el basalto/andesita, la calcedonia y las rocas silíceas, mientras que hacia el Holoceno Tardío final predomina el empleo de rocas silíceas y calcedonias, tanto de procedencia areal como extra-areal (Armentano 2012). Dentro de este último grupo, se registran en los conjuntos materias primas procedentes de regiones ubicadas al norte (Tandilia y Ventania, ca. $350 \mathrm{~km}$ y $200 \mathrm{~km}$ del área de estudio, 
respectivamente), sur (Golfo San Matías y/o Meseta de Somuncurá, ca. 300 km y 680 km del área de estudio, respectivamente) y oeste (Meseta del Fresco, Laguna El Carancho y Bajos sin Salida; ca. 400 km, 250 km y 80 km del área de estudio, respectivamente) del CIRC (Figura 3). Si bien las frecuencias con las que aparecen en cada momento varían, se propone que se habrían empleado las mismas estrategias de aprovisionamiento a lo largo del tiempo. En este sentido, la obtención de aquellas rocas de Ventania y alrededores (metacuarcita y arenisca cuarzosa; Bayón et al. 1999, 2010, entre otros) fue resultado de un aprovisionamiento directo en los afloramientos y/o depósitos secundarios asociados, aunque no se descartaron estrategias de aprovisionamiento indirecto operando en forma simultánea (Santos Valero 2015, 2017; Santos Valero y Martínez 2019).

Por otro lado, las materias primas procedentes de las sierras de Tandilia (ortocuarcitas; Bayón et al.1999; Colombo 2011; Flegenheimer et al. 1996; entre otros), la Meseta del Fresco (chert silíceo; Berón 2004; Carrera Aizpitarte 2014; entre otros), la Laguna El Carancho (chert; Carrera Aizpitarte 2014), los Bajos sin Salida (sílice sedimentario; Carrera Aizpitarte 2014) y el Golfo San Matías y/o la Meseta de Somuncurá (calcedonias translúcidas; Alberti y Cardillo 2015; Hermo y Terranova 2016; entre otros) habrían sido adquiridas en ambos periodos a través de mecanismos de intercambio (Armentano 2012; Santos Valero 2015, 2017; Santos Valero y Martínez 2019).
La producción se llevó a cabo empleando seis modalidades que involucraron el trabajo sobre soportes tallados (i.e. lascas, hemiguijarros, núcleos, desechos indeterminables) y naturales o no tallados (i.e., rodados, plaquetas y nódulos). En este sentido, se registró la delineación de filos, el façonnage y la modificación por uso tanto de soportes tallados como naturales, así como la modificación mediante las técnicas de picado, abrasión y pulido de soportes naturales (Santos Valero 2015, 2017). Los soportes tallados fueron generados empleando diferentes métodos de débitage (unipolar corto, bipolar, centrípeto, facial y en rodajas, entre otros; Armentano 2012; Santos Valero 2017). Mientras que la producción durante el Holoceno Medio (sitio La Modesta) y Tardío inicial (sitios El Caldén, El Puma 3, Campo Monaldi 1 y 2, Loma Ruiz 1, entre otros) se realizó a partir de una amplia variedad de métodos (principalmente unipolar corto, bipolar, centrípeto y facial), y hacia el lapso final del Holoceno se desarrolló principalmente mediante el débitage centrípeto y bipolar (sitio El Tigre y localidad arqueológica San Antonio; Armentano 2012; Santos Valero 2015, 2017). En relación a los instrumentos, aquellos sitios donde se desarrollaron actividades residenciales durante el Holoceno Medio y Tardío inicial muestran gran diversidad de grupos tipológicos, mayoritariamente instrumentos compuestos, filos en bisel asimétrico unifacial, raspadores, lascas con rastros complementarios y percutores. Esta situación cambia hacia el Holoceno Tardío final cuando la producción

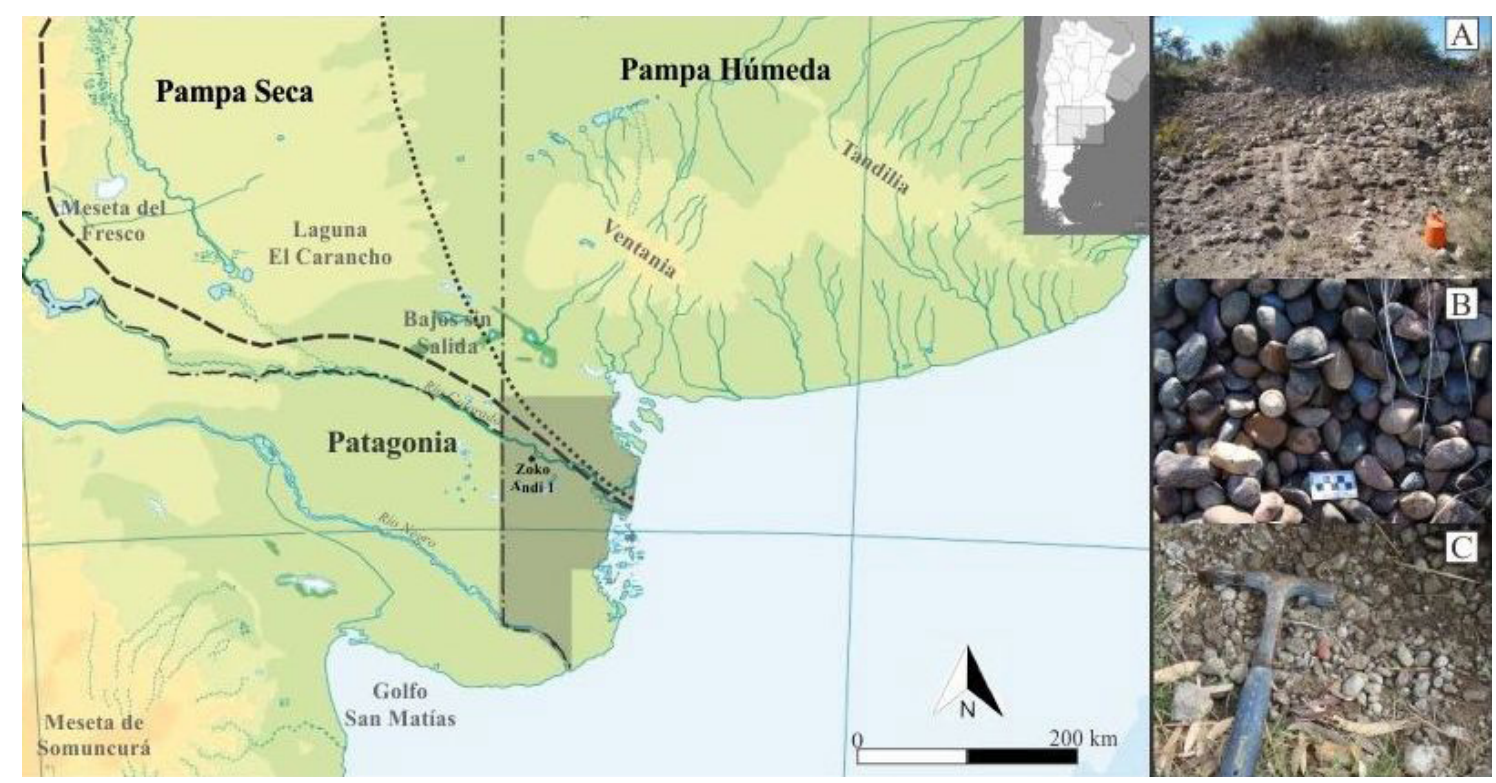

Figura 3. Izquierda: Afloramientos de rocas extra-areales registradas en Zoko Andi 1. Derecha: Afloramientos de rocas areales: (A) areniscas rionegrenses; (B) rodados costeros y (C) rodados Patagónicos.

Left: Outcrops of exotic rocks recorded in Zoko Andi 1. Right: Areal rock outcrops: (A) Rionegrense sandstones; (B) coastal pebbles and (C) Patagonic pebbles. 
se concentra en la confección de puntas de proyectil y raspadores. En comparación con las ocupaciones anteriores, la producción de estos instrumentos muestra características más estandarizadas en cuanto a las etapas de confección y diseño (Armentano 2012; Santos Valero 2017; Santos Valero y Armentano 2017).

\section{Muestra y Metodología}

La muestra analizada comprende los artefactos líticos procedentes de las Cuadrículas 4, 6, 11 y 13 (Figura 1B), diferenciándolos según correspondieran al Componente Superior o Inferior. Este conjunto fue elegido dado que los materiales de estas cuadrículas fueron abordados con igual profundidad desde las líneas de evidencia anteriormente mencionadas (tafonomía, zooarqueología, geomorfología, tecnología cerámica), lo cual permitirá una mejor integración de todos los resultados para entender la funcionalidad del sitio. El estudio aquí desarrollado se orientó a conocer sus características tecnomorfológicas, así como las operaciones de talla mediante el análisis de cadenas operativas, con el fin de establecer las etapas y fases de la transformación de la materia prima, considerando el conocimiento o "saber hacer" y la intención del tallador/a para obtener productos deseados (Inizan et al. 1995; LeroiGourhan 1971 [1964]; Turq 2000; entre otros). Para el análisis tecnomorfológico se tomaron variables propuestas por Aschero (1975, 1983), Aschero y Hocsman (2004), Babot (2004) y Tixier (1963). El análisis de cadenas operativas se llevó a cabo considerando las propuestas de diferentes investigadores provenientes de distintas corrientes de la Escuela Francesa (Boëda 2000; Inizan et al. 1995; Marchand 1999; Pelegrin 1995; entre otros). Para identificar los métodos y técnicas de talla empleados en los conjuntos y algunos grupos tipológicos se siguió también la propuesta de Armentano (2012) desarrollada para el área de estudio. Esta última se basa en el estudio de la explotación de núcleos sobre rodados. Los métodos de débitage se determinan considerando si las extracciones fueron realizadas de manera secante, longitudinal o perpendicular al eje mayor del rodado. Estas diferentes modalidades permiten la obtención de soportes con características particulares (p.ej., más largos que anchos, cortos y anchos, etc.).

Con respecto a la clasificación de las materias primas, de manera heurística se consideran areales a todas aquellas rocas que se pueden obtener dentro del área de estudio (Figura 3 A y B), abarcando diferentes litologías (p.ej., basaltos/andesitas, riolitas, dacitas, rocas silíceas, calcedonias, etc.) bajo la forma de rodados, tanto Patagónicos (Manto Tehuelche) como costeros, así como las denominadas areniscas rionegrenses (Santos Valero 2017). Esta categoría, si bien es amplia, resulta operativa para poder abarcar la totalidad de materias primas disponibles en el área de estudio, considerando el carácter heterogéneo de los afloramientos en el paisaje y la dificultad para identificar su localización en el campo. Esto, a su vez, impide establecer de manera precisa rangos de distancias en kilómetros cuando se consideran sitios particulares. Por otro lado, se han registrado en los conjuntos artefactuales materias primas cuyos afloramientos se encuentran fuera del área de estudio y que son consideradas, por lo tanto, extra-areales. Su identificación fue posible mediante la comparación macroscópica con muestras de mano de rocas de áreas aledañas, la búsqueda bibliográfica y la realización de cortes petrográficos (Martínez y Santos Valero 2020). Como resultado se constató la presencia de materias primas procedentes de Pampa Húmeda, Seca y Norpatagonia (Armentano 2012; Martínez y Santos Valero 2020; Santos Valero 2017).

\section{Resultados}

A continuación se desarrollarán las principales características del conjunto lítico, discriminando entre componentes. Como se observa en la Figura 2, el material lítico se encuentra distribuido a lo largo de toda la secuencia estratigráfica, mostrando concentraciones entre los niveles $2,65 \mathrm{~m}$ y $2,80 \mathrm{~m}$ del Componente Superior (U4 a 1). En el Componente Inferior (U6 y 5) se observa una menor cantidad de hallazgos, pero una distribución de artefactos más homogénea en relación a los niveles suprayacentes (Figura 2; Martínez et al. 2014).

\section{ZA 1 CI}

El Componente Inferior del sitio está integrado por 784 artefactos, donde predominan los desechos de talla, seguidos en frecuencia por los desechos indiferenciados (Tabla 1). Dentro de las materias primas, las rocas silíceas representan casi la mitad del conjunto (Tabla 1). Con respecto a las rocas extra-areales, predominan las calcedonias translúcidas con el 4,2\%, mientras que el resto no supera en ningún caso el $2 \%$. La mayoría de los artefactos se recuperaron fracturados (68\%).

El $82 \%$ de los instrumentos corresponde a aquellos confeccionados sobre soportes tallados, mientras que el $18 \%$ restante pertenece a instrumentos confeccionados sobre soportes no tallados. Entre los primeros se destacan los raspadores, lascas con rastros complementarios y puntas de proyectil (Tabla 2; Figura 4). Estos instrumentos fueron confeccionados mayoritariamente sobre rocas areales, sobresaliendo las rocas silíceas y calcedonias. Se registran también instrumentos sobre materias primas extra-areales como la calcedonia translúcida, metacuarcita y ortocuarcita (Tabla 2).

Los soportes empleados para los instrumentos fueron preferentemente lascas, destacándose las indiferenciadas y las angulares (Tabla 3). Entre las lascas que presentan talón, están representados los lisos, filiformes, lisos naturales y uno diedro (Tabla 3). Las dimensiones relativas permiten observar la 
Tabla 1. Categorías artefactuales, ecofactos y materias primas representadas en el Componente Inferior de Zoko Andi 1. Referencias: Desechos ind.: Desechos indiferenciados; Inst. soportes tallados: Instrumentos sobre soportes tallados; Inst. soportes no tallados: Instrumentos sobre soportes no tallados, Calcedonia tr: Calcedonia translúcida.

Artifactual categories, ecofacts and raw materials represented in the Lower Component of Zoko Andi 1. References: Desechos ind.: chunk; Inst. soportes tallados: tools on debitaged blanks, Inst. soportes no tallados: tools on non debitaged blanks; Calcedonia tr: translucent chalcedony.

\begin{tabular}{|c|c|c|c|c|c|c|c|c|c|c|c|}
\hline \multirow[b]{2}{*}{$\begin{array}{c}\text { Procedencia } \\
\text { materias } \\
\text { primas }\end{array}$} & \multirow[b]{2}{*}{ Materia prima } & \multicolumn{7}{|c|}{ Artefactos } & \multirow[b]{2}{*}{ Ecofactos } & \multirow[b]{2}{*}{ Total } & \multirow[b]{2}{*}{$\%$} \\
\hline & & 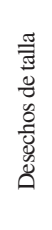 & 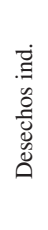 & 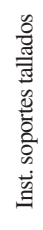 & 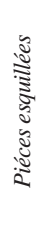 & $\frac{\ddot{d}}{\frac{d}{e}}$ & 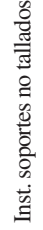 & 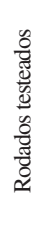 & & & \\
\hline \multirow{13}{*}{ Areales } & Rocas silíceas & 312 & 35 & 20 & 5 & 4 & - & 1 & - & 377 & 48,1 \\
\hline & Calcedonia & 120 & 14 & 5 & 1 & 1 & - & - & - & 141 & 18 \\
\hline & Basalto/andesita & 46 & 2 & 1 & 1 & - & - & - & 1 & 51 & 6,5 \\
\hline & Indeterminable & 23 & 18 & - & - & - & - & - & 1 & 42 & 5,4 \\
\hline & Arenisca rionegrense & 2 & 28 & - & - & - & 5 & - & - & 35 & 4,5 \\
\hline & Riolita & 15 & 2 & 1 & - & 1 & - & - & 1 & 20 & 2,6 \\
\hline & Dacita & 14 & 1 & - & 1 & - & 1 & - & 1 & 18 & 2,3 \\
\hline & Tufita & 16 & 1 & - & - & - & - & - & - & 17 & 2,2 \\
\hline & Xilópalo & 7 & 2 & 1 & - & 1 & - & - & - & 11 & 1,4 \\
\hline & Granitoide & 6 & 1 & - & - & - & - & - & - & 7 & 0,9 \\
\hline & Obsidiana & 4 & - & - & - & - & - & - & - & 4 & 0,5 \\
\hline & Pumicita & - & - & - & - & - & 1 & - & - & 1 & 0,1 \\
\hline & Cuarzo & 1 & - & - & - & - & - & - & - & 1 & 0,1 \\
\hline \multirow{9}{*}{ Extra-areales } & Calcedonia tr. & 29 & 1 & 2 & 1 & - & - & - & - & 33 & 4,2 \\
\hline & Ortocuarcita & 9 & - & 1 & - & - & - & - & - & 10 & 1,3 \\
\hline & Arenisca cuarzosa & 1 & 4 & - & - & - & - & - & - & 5 & 0,6 \\
\hline & Metacuarcita & 2 & 1 & 1 & - & - & - & - & - & 4 & 0,5 \\
\hline & Chert & 3 & - & - & - & - & - & - & - & 3 & 0,4 \\
\hline & Sílice sedimentario & 2 & - & - & - & - & - & - & - & 2 & 0,3 \\
\hline & Chert silíceo & 2 & - & - & - & - & - & - & - & 2 & 0,3 \\
\hline & Total & 614 & 110 & 32 & 9 & 7 & 7 & 1 & 4 & 784 & 100 \\
\hline & $\%$ & 78,3 & 14 & 4,1 & 1,1 & 0,9 & 0,9 & 0,1 & 0,5 & 100 & - \\
\hline
\end{tabular}

Tabla 2. Instrumentos recuperados en ZA1 CI. Referencias: Arenisca r.: Arenisca rionegrense; Calcedonia tr.: Calcedonia translúcida; Artefacto Indef. Pos. Indet: Artefacto de molienda indefinido de posición indeterminada.

Tools recovered in ZA 1 CI. References: Arenisca r.: Rionegrense sandstone; Calcedonia tr.: Translucent chalcedony; Artefacto Indef. Pos. Indet.: Indefinite artifact of indeterminate position.

\begin{tabular}{|c|c|c|c|c|c|c|c|c|c|c|c|c|c|c|}
\hline & $\begin{array}{l}\text { Materia prima-Grupo } \\
\text { tipológico }\end{array}$ & 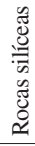 & 怨 & $\begin{array}{l}\frac{\pi}{U} \\
\frac{0}{0} \\
\frac{0}{\pi} \\
\tilde{J}\end{array}$ & 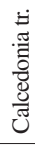 & 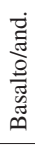 & 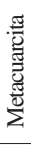 & 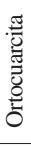 & $\frac{\pi}{0}$ & $\frac{0}{\frac{0}{\pi}}$ & 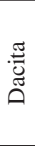 & : & Total & $\%$ \\
\hline \multirow{10}{*}{$\begin{array}{c}\text { Instrumentos } \\
\text { sobre soportes } \\
\text { tallados }\end{array}$} & Raspador & 11 & - & 2 & 1 & - & - & - & - & - & - & - & 14 & 36 \\
\hline & $\begin{array}{l}\text { Lasca con rastros } \\
\text { complementarios }\end{array}$ & 1 & - & 1 & 1 & 1 & - & 1 & 1 & - & - & - & 6 & 15 \\
\hline & Punta de proyectil & 3 & - & 1 & - & - & - & - & - & - & - & - & 4 & 10 \\
\hline & Filo bifacial & 2 & - & - & - & - & - & - & - & - & - & - & 2 & 5 \\
\hline & Instrumento compuesto & 2 & - & - & - & - & - & - & - & - & - & - & 2 & 5 \\
\hline & Instrumento bifacial & - & - & - & - & - & 1 & - & - & - & - & - & 1 & 3 \\
\hline & Filo en bisel asimétrico & 1 & - & - & - & - & - & - & - & - & - & - & 1 & 3 \\
\hline & Punta destacada & 1 & - & - & - & - & - & - & - & - & - & - & 1 & 3 \\
\hline & Esbozos y preformas & - & - & - & - & - & - & - & - & 1 & - & - & 1 & 3 \\
\hline & Subtotal & 21 & - & 4 & 2 & 1 & 1 & 1 & 1 & 1 & - & - & 32 & 82 \\
\hline
\end{tabular}


Continuación Tabla 2.

\begin{tabular}{|c|c|c|c|c|c|c|c|c|c|c|c|c|c|c|}
\hline & $\begin{array}{l}\text { Materia prima-Grupo } \\
\text { tipológico }\end{array}$ & 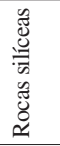 & 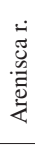 & $\begin{array}{l}\cdot \frac{\pi}{3} \\
\frac{0}{0} \\
\frac{0}{\pi} \\
\tilde{J}\end{array}$ & 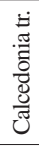 & 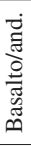 & 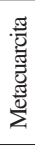 & 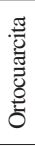 & $\frac{\pi}{\mathscr{0}} \frac{\pi}{0}$ & $\frac{\frac{0}{\pi}}{\frac{20}{\pi}}$ & 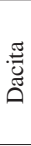 & . & Total & $\%$ \\
\hline \multirow{9}{*}{$\begin{array}{c}\text { Instrumentos } \\
\text { sobre soportes } \\
\text { no tallados }\end{array}$} & Artefacto Indef. pos. Indet. & - & 2 & - & - & - & - & - & - & - & - & - & 2 & 5 \\
\hline & Bola de boleadora & - & 1 & - & - & - & - & - & - & - & - & - & 1 & 3 \\
\hline & Yunque & - & 1 & - & - & - & - & - & - & - & - & - & 1 & 3 \\
\hline & $\begin{array}{c}\text { Artefacto Pasivo } \\
\text { Indefinido }\end{array}$ & - & 1 & - & - & - & - & - & - & - & - & - & 1 & 3 \\
\hline & Percutor & - & - & - & - & - & - & - & - & - & 1 & - & 1 & 3 \\
\hline & Instrumento indeterminado & - & - & - & - & - & - & - & - & - & - & 1 & 1 & 3 \\
\hline & Subtotal & - & 5 & - & - & - & - & - & - & - & 1 & 1 & 7 & 18 \\
\hline & Total & 21 & 5 & 4 & 2 & 1 & 1 & 1 & 1 & 1 & 1 & 1 & 39 & 100 \\
\hline & $\%$ & 54 & 13 & 10 & 5 & 3 & 3 & 3 & 3 & 3 & 3 & 3 & 100 & \\
\hline
\end{tabular}
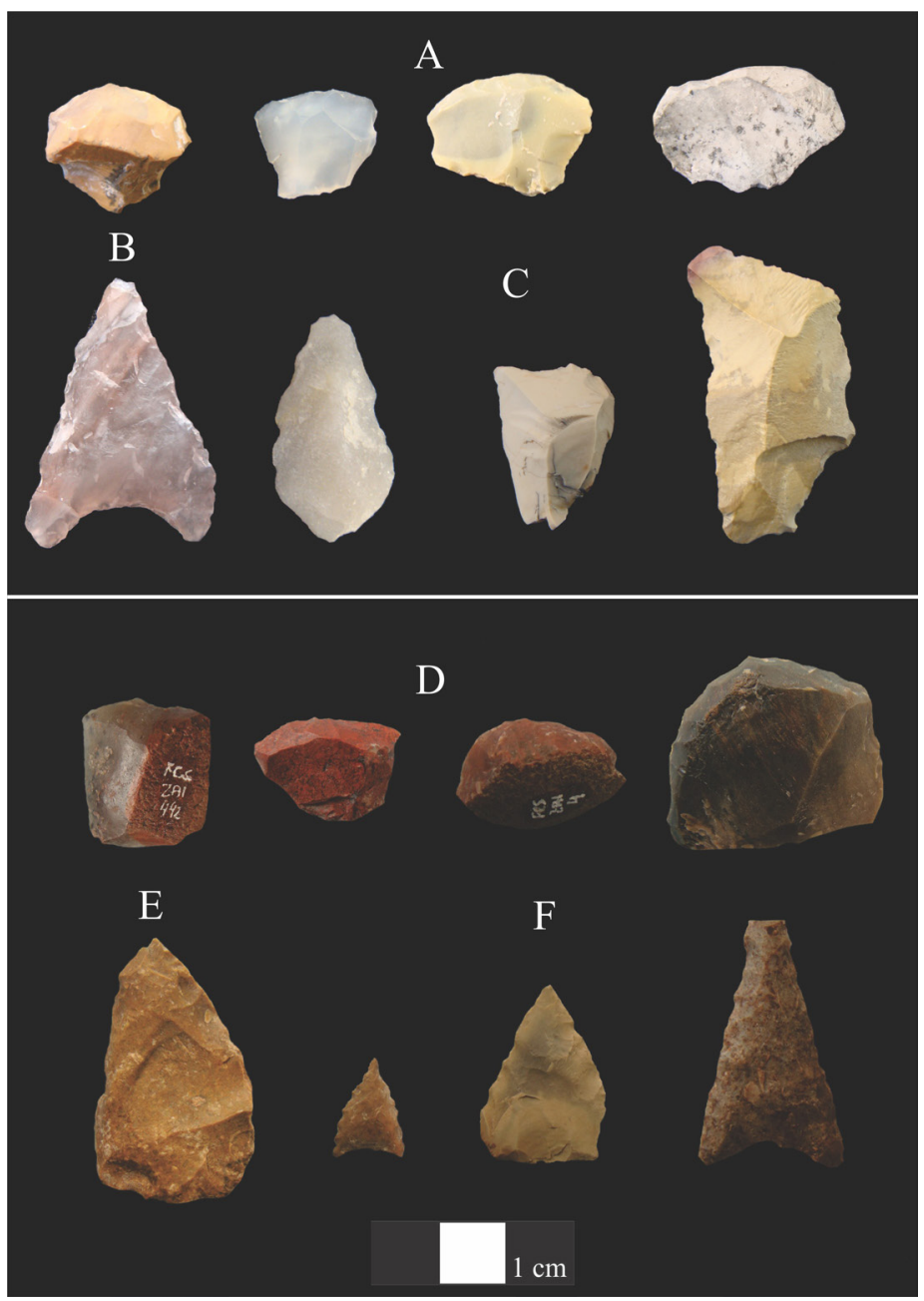

Figura 4. Instrumentos recuperados en el Componente Inferior (arriba) y Superior (abajo) de Zoko Andi 1. Referencias: (A) Raspadores; (B) punta de proyectil; (C) instrumentos compuestos; (D) Raspadores; (E) esbozo bifacial; (F) puntas de proyectil.

Tools recovered from the Lower (above) and Upper (down) components of Zoko Andi 1. References: (A) Endscrapers; (B) Projectile point; (C) Composed tools; (D) Endscrapers; (E) Bifacial roughout; (F) Projectile points. 
Tabla 3. Soportes empleados para la confección de los instrumentos sobre soportes tallados recuperados en los Componentes Inferior y Superior. Se exponen detalles sobre la variabilidad de lascas empleadas y los talones representados en cada una. También se indican las series técnicas utilizadas para la delineación de los filos de estos instrumentos. Debido a que se cuenta con instrumentos de filos dobles o triples, algunos de ellos realizados mediante series técnicas diferentes (i.e., instrumentos compuestos), las cantidades y frecuencias de las series técnicas en ambos conjuntos están calculadas en función de la totalidad de filos y superficies activas de los instrumentos, y no del número total de piezas. Referencias: ZA 1 CI: Zoko Andi 1 Componente Inferior; ZA 1 CS: Zoko Andi 1 Componente Superior; R.: retoque; M. microretoque; T.: talla y Ma.: machacado.

Blanks employed in the manufacturing of the tools on debitaged blanks recovered in the Lower and Upper Components. Details on the variability of the flakes employed and the kind of platforms represented are shown. The technical series used for the preparation of the edges are also indicated. Because of the presence of double and triple-edged tools, some of them made by using different technical series (i.e. composed tools), the quantities and frequencies of the technical series in both assemblages were calculated on the basis of the total number of active edges and surfaces rather than the total number of pieces.

\begin{tabular}{|c|c|c|c|c|}
\hline & \multicolumn{2}{|c|}{$\mathrm{ZA} 1 \mathrm{CI}$} & \multicolumn{2}{|c|}{$\mathrm{ZA} 1 \mathrm{CS}$} \\
\hline & $\mathrm{N}$ & $\%$ & $\mathrm{~N}$ & $\%$ \\
\hline \multicolumn{5}{|c|}{ Soporte } \\
\hline Indeterminable & 4 & 13 & 22 & 20 \\
\hline Lasca & 28 & 88 & 86 & 78 \\
\hline Hemiguijarro & - & - & 1 & 1 \\
\hline Núlceo & - & - & 1 & 1 \\
\hline Total & 32 & 100 & 110 & 100 \\
\hline \multicolumn{5}{|c|}{ Lasca soporte } \\
\hline Angular & 7 & 25 & 17 & 20 \\
\hline Arista & 5 & 18 & 11 & 13 \\
\hline Dorso natural & 3 & 11 & 6 & 7 \\
\hline Primaria & 2 & 7 & 6 & 7 \\
\hline Indeterminable & 10 & 36 & 34 & 40 \\
\hline Plana & 1 & 4 & 3 & 3 \\
\hline Secundaria & - & - & 9 & 10 \\
\hline Total & 28 & 100 & 86 & 100 \\
\hline \multicolumn{5}{|c|}{ Talones } \\
\hline Ausentes & 16 & 57 & 52 & 60 \\
\hline Liso & 5 & 18 & 9 & 10 \\
\hline Liso natural & 2 & 7 & 11 & 13 \\
\hline Filiforme & 4 & 14 & 7 & 8 \\
\hline Diedro & 1 & 4 & - & - \\
\hline Facetado & - & - & 4 & 5 \\
\hline Natural cortical & - & - & 3 & 3 \\
\hline Total & 28 & 100 & 86 & 100 \\
\hline \multicolumn{5}{|c|}{ Series técnicas } \\
\hline R. marginal & 26 & 55 & 39 & 21 \\
\hline R. extendido & 14 & 30 & 93 & 49 \\
\hline T. extendida y R. marginal & 2 & 4 & 20 & 11 \\
\hline T. parcialmente extendida & 3 & 6 & - & - \\
\hline T. extendida & 2 & 4 & 5 & 3 \\
\hline M. marginal & - & - & 9 & 5 \\
\hline R. parcialmente extendido & - & - & 6 & 3 \\
\hline R. extendido y M. ultramarginal & - & - & 4 & 2 \\
\hline R. marginal y Ma. Extendido & - & - & 3 & 2 \\
\hline R. parcialmente extendido y R. marginal & - & - & 3 & 2 \\
\hline R. ultramarginal & - & - & 3 & 2 \\
\hline R. extendido y R. marginal & - & - & 2 & 1 \\
\hline T. extendida y Ma. & - & - & 1 & 1 \\
\hline Total & 47 & 100 & 188 & 100 \\
\hline
\end{tabular}


predominancia de instrumentos pequeños $(47 \%)$ y espesos (37\%). En líneas generales, los filos se delinearon mediante retoques marginales y extendidos (Tabla 3).

Particularmente con respecto a las características de aquellos grupos tipológicos mejor representados, los raspadores (Figura 4A) fueron confeccionados exclusivamente sobre rocas silíceas y calcedonias (Tabla 2). Se trata de artefactos pequeños (79\%) que presentan variabilidad de espesores (espesos-36\%-, muy espesos-29\%- y poco espesos-21\%-) y que fueron descartados al final de su vida útil, hallándose ocho embotados y dos reactivados. Las lascas con rastros complementarios presentan una gran diversidad de materias primas y tamaños, teniendo como único patrón reconocible la elección de lascas espesas (50\%). Por último, las cuatro puntas de proyectil recuperadas se realizaron exclusivamente sobre rocas silíceas y calcedonias (Tabla 2), registrándose solo una de ellas entera. Esta última se trata de una punta triangular apedunculada mediana (Figura 4B), confeccionada sobre una lasca espesa de calcedonia de origen extra-areal. Para su realización se rebajó unifacialmente el soporte y se delinearon los filos por medio de retoques bifaciales.

Los instrumentos confeccionados sobre soportes no tallados comprenden fragmentos de diversos instrumentos, como artefactos de molienda, fragmentos de una bola de boleadora, un yunque y un percutor (Tabla 2). En este conjunto las rocas más frecuentes son las areniscas rionegrenses. Debido al alto grado de fragmentación que presentan estos artefactos, no fue posible identificar los soportes elegidos ni las dimensiones relativas. La única excepción la comprende el percutor, realizado sobre un rodado ovalado, grande y muy espeso. El resto se corresponde a fragmentos de artefactos que no superan $\operatorname{los} 6 \mathrm{~cm}$ de largo y $5 \mathrm{~cm}$ de ancho.

Las pièces esquillées ${ }^{1}$ fueron confeccionadas preferentemente sobre rocas silíceas (Tabla 1). Los soportes seleccionados fueron en su mayoría lascas (78\%), destacándose las indeterminables (57\%). También se recuperaron pièces esquillées desarrolladas sobre un rodado chato y un soporte indeterminable ( $11 \%$ cada uno). Se trata de artefactos preferentemente pequeños (57\%) y espesos (89\%).

Dentro de este conjunto se cuenta con un rodado testeado y siete núcleos. Estos últimos fueron desarrollados sobre rodados de diferentes morfologías (72\%), así como sobre una lasca y un soporte indeterminado ( $14 \%$, cada uno). Con relación a las materias primas, predominan las rocas silíceas (Tabla 1). Se trata de artefactos mayoritariamente pequeños, mediano pequeños (43\% cada uno) y muy espesos (71\%). Se identificaron cuatro núcleos bipolares (57\%) y uno prismático parcial (14\%). En lo que respecta a la cantidad de plataformas, los núcleos presentan equitativamente tanto una como dos (43\% en cada caso), con un solo ejemplar que presenta plataformas múltiples (14\%). Dos núcleos se registraron agotados y uno rotado.

La categoría de desechos de talla está compuesta por 381 lascas (62\%), 232 microlascas $(37,8 \%$ ) y un bâtonnet ${ }^{2}(0,2 \%)$. Las rocas representadas en esta categoría artefactual son principalmente las rocas silíceas, calcedonias y basaltos/andesitas (Tabla 1). Entre las lascas predominan las indiferenciadas (46\%), de arista recta (15\%), de dorso natural y primarias (7\%). Los talones mejor representados son los filiformes (69\%), seguidos en frecuencia por los lisos naturales (14\%), estando representados en frecuencias menores al $5 \%$ los lisos, naturales corticales, puntiformes, facetados y diedros. Se destaca la presencia de desechos muy pequeños $(54 \%)$ y pequeños $(25 \%)$, espesos $(36 \%)$ y poco espesos $(27 \%)$.

\section{ZA 1 CS}

El Componente Superior comprende 7.646 artefactos líticos, de los cuales casi el $90 \%$ son desechos de talla (Tabla 4). A estos le siguen en mucha menor proporción los desechos indiferenciados, mientras que el resto de las categorías no superan el $2 \%$ del conjunto (Tabla 4). En relación a las materias primas, nuevamente son las rocas silíceas las más abundantes, seguidas en frecuencia por las calcedonias (Tabla 4). Las rocas extra-areales presentan porcentajes menores al 5\%, entre las cuales las calcedonias translúcidas muestran los valores más altos (Tabla 4), siendo las cuartas en orden de representación en todo el conjunto. La muestra se encuentra comprendida mayormente por artefactos fracturados (57\%).

Entre los instrumentos sobre soportes tallados (85\%), las puntas de proyectil y los raspadores son los más abundantes (Tabla 5; Figura 4D y F), confeccionados preferentemente sobre rocas silíceas, y en menor proporción sobre calcedonia y calcedonia translúcida (Tabla 5). Los soportes elegidos para estos instrumentos fueron en su mayoría lascas, aunque también se emplearon soportes indiferenciados, un núcleo y un hemiguijarro (Tabla 3 ). Entre las primeras se destacan las indeterminables, secundarias y de arista recta (Tabla 3). Con respecto a los talones presentes, predominan los lisos naturales y lisos (Tabla 3). En líneas generales son instrumentos pequeños (50\%) y espesos (37\%). Las series técnicas más empleadas fueron el retoque extendido y el retoque marginal (Tabla 3 ).

En particular con respecto a las puntas de proyectil (Figura 4F), se observa la presencia de apedunculadas de tamaños mediano (18\%), pequeño $(46 \%)$ e indeterminable (36\%), confeccionadas 
Tabla 4. Categorías artefactuales, ecofactos y materias primas representadas en el Componente Superior de Zoko Andi 1. Referencias: Desechos ind.: Desechos indeterminables; Inst. soportes tallados: Instrumentos sobre soportes tallados; Inst. soportes no tallados: Instrumentos sobre soportes no tallados; Inst./núcleos: Instrumentos/núcleos; Arenisca r.: Arenisca rionegrense;

Calcedonia tr.: Calcedonia translúcida; Arenisca c.: Arenisca cuarzosa; Cuarcita ind.: Cuarcita indeterminable.

Artifactual categories, ecofacts and raw materials represented in the Upper Component of Zoko Andi 1. References: Desechos ind.: chunk; Inst. soportes tallados: tools on debitaged blanks, Inst. soportes no tallados: tools on non debitaged blanks; Instrumentos/núcleos: Tools on cores; Arenisca $r$. Rionegrense sandstone; Calcedonia tr.: translucent chalcedony; Arenisca c.: Quartz sandstone; Cuarcita ind.: Indeterminate quartzite.

\begin{tabular}{|c|c|c|c|c|c|c|c|c|c|c|c|c|c|}
\hline \multirow[b]{2}{*}{$\begin{array}{l}\text { Procedencia } \\
\text { materias primas }\end{array}$} & \multirow[b]{2}{*}{ Materia prima } & \multicolumn{9}{|c|}{ Artefactos } & \multirow[b]{2}{*}{ Ecofactos } & \multirow[b]{2}{*}{ Total } & \multirow[b]{2}{*}{$\%$} \\
\hline & & 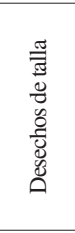 & 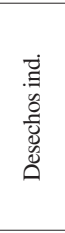 & 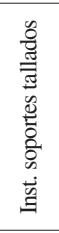 & 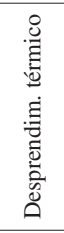 & 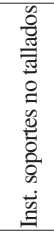 & $\begin{array}{l}\frac{n}{0} \\
\frac{0}{\tilde{g}} \\
\stackrel{\Xi}{z}\end{array}$ & 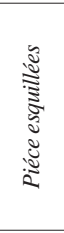 & 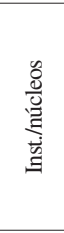 & 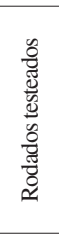 & & & \\
\hline \multirow{15}{*}{ Areales } & Rocas silíceas & 4.407 & 250 & 74 & 19 & 6 & 4 & 2 & - & - & 1 & 4.763 & 62,29 \\
\hline & Calcedonia & 1.263 & 45 & 17 & 3 & 1 & 4 & 2 & - & - & 1 & 1.336 & 17,47 \\
\hline & Indeterminable & 277 & 105 & 1 & 1 & - & 1 & - & - & - & 1 & 386 & 5,05 \\
\hline & Dacita & 170 & 6 & 1 & - & 1 & - & - & - & - & - & 178 & 2,33 \\
\hline & Tufita & 131 & 17 & 1 & 1 & - & 1 & - & 1 & - & - & 152 & 1,99 \\
\hline & Basalto/andesita & 118 & 13 & 3 & - & - & 1 & - & - & - & 1 & 136 & 1,78 \\
\hline & Arenisca $\mathrm{r}$. & 15 & 108 & - & - & 8 & - & - & - & - & - & 131 & 1,71 \\
\hline & Riolita & 55 & 7 & 1 & - & 2 & 2 & - & - & 1 & 2 & 70 & 0,92 \\
\hline & Xilópalo & 18 & 2 & 3 & - & - & - & - & - & - & - & 23 & 0,30 \\
\hline & Cuarzo & 12 & 9 & - & - & - & - & - & - & - & - & 21 & 0,27 \\
\hline & Obsidiana & 8 & - & - & - & - & - & - & - & - & - & 8 & 0,10 \\
\hline & Agata & 2 & - & - & - & - & - & - & - & - & - & 2 & 0,03 \\
\hline & Pumicita & - & - & - & - & 2 & - & - & - & - & - & 2 & 0,03 \\
\hline & Granitoide & 1 & - & - & - & - & - & - & - & - & - & 1 & 0,01 \\
\hline & Tosca & - & 1 & - & - & - & - & - & - & - & - & 1 & 0,01 \\
\hline \multirow{10}{*}{ Extra-areales } & Calcedonia tr. & 330 & 22 & 7 & 1 & - & - & - & - & - & - & 360 & 4,71 \\
\hline & Ortocuarcita & 24 & 3 & - & - & - & - & - & - & - & - & 27 & 0,35 \\
\hline & $\begin{array}{c}\text { Sílice } \\
\text { sedimentario }\end{array}$ & 17 & 1 & - & - & - & - & - & - & - & - & 18 & 0,24 \\
\hline & Chert & 15 & - & 1 & - & - & - & - & - & - & - & 16 & 0,21 \\
\hline & Metacuarcita & 6 & 1 & - & - & - & - & - & - & - & - & 7 & 0,09 \\
\hline & Arenisca c. & - & 4 & - & - & - & - & - & - & - & - & 4 & 0,05 \\
\hline & Cuarcita ind. & 3 & - & - & - & - & - & - & - & - & - & 3 & 0,04 \\
\hline & Limolita & - & - & - & - & - & - & 1 & - & - & - & 1 & 0,01 \\
\hline & Total & 6.872 & 594 & 109 & 25 & 20 & 13 & 5 & 1 & 1 & 6 & 7.646 & 100 \\
\hline & $\%$ & 89,88 & 7,77 & 1,43 & 0,33 & 0,26 & 0,17 & 0,07 & 0,01 & 0,01 & 0,08 & 100 & - \\
\hline
\end{tabular}


Tabla 5. Instrumentos recuperados en ZA1 CS. Referencias: Arenisca r.: Arenisca rionegrense; Calcedonia tr.: Calcedonia translúcida; Artefacto Indef. Pos. Indet: Artefacto de molienda indefinido de posición indeterminada.

Tools recovered in ZA 1 CS. References: Arenisca r.: Rionegrense sandstone; Calcedonia tr.: Translucent chalcedony; Artefacto Indef. Pos. Indet.: Indefinite artifact of indeterminate position.

\begin{tabular}{|c|c|c|c|c|c|c|c|c|c|c|c|c|c|c|c|}
\hline & $\begin{array}{l}\text { Materia prima-Grupo } \\
\text { tipológico }\end{array}$ & 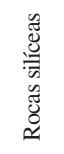 & 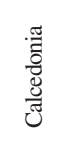 & 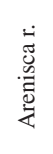 & 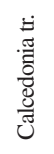 & $\begin{array}{l}\stackrel{\frac{\pi}{0}}{0} \\
: \frac{0}{2}\end{array}$ & 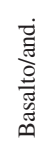 & 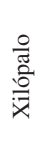 & 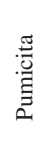 & $\begin{array}{l}\stackrel{0}{0} \\
\stackrel{0}{\pi} \\
0\end{array}$ & 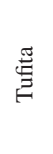 & ड़ & 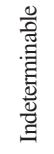 & Total & $\%$ \\
\hline \multirow{13}{*}{$\begin{array}{l}\text { Instrumentos } \\
\text { sobre soportes } \\
\text { tallados }\end{array}$} & Punta de proyectil & 18 & 4 & - & 3 & - & 1 & 2 & - & - & - & - & - & 28 & 21,5 \\
\hline & Raspador & 19 & 2 & - & 1 & - & - & - & - & - & 1 & 1 & - & 24 & 18,5 \\
\hline & $\begin{array}{l}\text { Lasca con rastros } \\
\text { complementarios }\end{array}$ & 7 & 3 & - & - & - & 2 & - & - & 1 & - & - & - & 13 & 10 \\
\hline & Esbozos y preformas & 7 & 3 & - & 1 & - & - & 1 & - & - & - & - & - & 12 & 9,2 \\
\hline & Instrumento compuesto & 6 & 3 & - & - & 1 & - & - & - & - & - & - & 1 & 11 & 8,5 \\
\hline & $\begin{array}{l}\text { Lasca con retoque } \\
\text { sumario }\end{array}$ & 8 & - & - & - & - & - & - & - & - & - & - & - & 8 & 6,2 \\
\hline & Instrumento bifacial & 2 & 1 & - & 1 & - & - & - & - & - & - & - & - & 4 & 3,1 \\
\hline & Perforador & 3 & - & - & - & - & - & - & - & - & - & - & - & 3 & 2,3 \\
\hline & Filo en bisel asimétrico & 2 & 1 & - & 1 & - & - & - & - & - & - & - & - & 4 & 3,1 \\
\hline & $\begin{array}{l}\text { Instrumento } \\
\text { indiferenciable }\end{array}$ & 1 & - & - & - & - & - & - & - & - & - & - & - & 1 & 0,8 \\
\hline & Muesca & 1 & - & - & - & - & - & - & - & - & - & - & - & 1 & 0,8 \\
\hline & $\begin{array}{l}\text { Pieza con borde } \\
\text { machacado }\end{array}$ & - & - & - & - & - & - & - & - & - & 1 & - & - & 1 & 0,8 \\
\hline & Subtotal & 74 & 17 & - & 7 & 1 & 3 & 3 & - & 1 & 2 & 1 & 1 & 110 & 85 \\
\hline \multirow{11}{*}{$\begin{array}{l}\text { Instrumento } \\
\text { sobre soportes } \\
\text { no tallados }\end{array}$} & $\begin{array}{l}\text { Artefacto Indef. pos. } \\
\text { Indet }\end{array}$ & - & - & 6 & - & - & - & - & 2 & - & - & - & - & 8 & 6,2 \\
\hline & Esbozos y preformas & 3 & 1 & - & - & - & - & - & - & - & - & - & - & 4 & 3,1 \\
\hline & Raspador & 2 & - & - & - & - & - & - & - & - & - & - & - & 2 & 1,5 \\
\hline & Mano molino & - & - & 2 & - & - & - & - & - & - & - & - & - & 2 & 1,5 \\
\hline & $\begin{array}{l}\text { Artefacto Activo } \\
\text { Indefinido }\end{array}$ & - & - & - & - & - & - & - & - & 1 & - & - & - & 1 & 0,8 \\
\hline & Yunque & - & - & - & - & 1 & - & - & - & - & - & - & - & 1 & 0,8 \\
\hline & Percutor & - & - & - & - & 1 & - & - & - & - & - & - & - & 1 & 0,8 \\
\hline & Instrumento compuesto & 1 & - & - & - & - & - & - & - & - & - & - & - & 1 & 0,8 \\
\hline & Subtotal & 6 & 1 & 8 & - & 2 & - & - & 2 & 1 & - & - & - & 20 & 15 \\
\hline & Total & 80 & 18 & 8 & 7 & 3 & 3 & 3 & 2 & 2 & 2 & 1 & 1 & 130 & 100 \\
\hline & $\%$ & 61,5 & 13,8 & 6,2 & 5,4 & 2,3 & 2,3 & 2,3 & 1,5 & 1,5 & 1,5 & 0,8 & 0,8 & 100 & \\
\hline
\end{tabular}

preferentemente sobre rocas silíceas (Tabla 5). La producción de las puntas apedunculadas medianas requirió la confección previa de preformas y esbozos para luego formatizar las piezas por medio de la reducción bifacial. En lo que respecta a las puntas apedunculadas pequeñas (espesas y poco espesas), se partió de lascas espesas reducidas bifacialmente a partir de retoques extendidos. En base a la presencia de un esbozo sobre una plaqueta de sílice, no se descarta que el façonnage de soportes naturales haya sido también una estrategia empleada para la producción de puntas, particularmente las apedunculadas medianas (muy espesas y espesas). Para los raspadores también se observa una preferencia por la utilización de rocas silíceas (Tabla 5), particularmente de las lascas de etapas avanzadas, de tamaños pequeños (81\%), tanto espesas como muy espesas (46\%, en cada caso). Gran cantidad de estos instrumentos se encuentran 
embotados $(43 \%)$. Finalmente es destacable la elevada presencia de preformas (Figura 4E) y esbozos bifaciales (Tabla 5), que se correspondería con la producción de puntas de proyectil, instrumentos bifaciales y perforadores.

Los instrumentos confeccionados sobre soportes no tallados $(15 \%)$ comprenden artefactos indefinidos, raspadores e instrumentos incompletos, realizados principalmente sobre arenisca rionegrense y rocas silíceas (Tabla 5). En aquellas piezas en que fue posible determinar el soporte seleccionado $(n=10)$, se estableció el empleo de ocho rodados de diferente morfología y dos plaquetas. En líneas generales, son instrumentos de tamaños mediano grande (30\%) y muy espesos $(35 \%)$. Si bien la mayoría de las piezas fueron desarrolladas por medio del picado, abrasión y pulido (70\%), otras como los raspadores, instrumentos compuestos y esbozos fueron confeccionadas a partir del retoque marginal y la talla extendida (10\%, para ambos casos), entre otras.

Las pièces esquillées fueron realizadas sobre rocas silíceas, calcedonias y limolita (Tabla 4). Como formas base se emplearon tres soportes indeterminables $(60 \%)$ y dos lascas primarias (40\%), trabajadas por medio del machacado bifacial extendido. Se trata en general de piezas muy espesas $(60 \%)$, de tamaños pequeño y mediano pequeño ( $40 \%$ en ambos casos, solo una pieza no pudo ser considerada debido a la presencia de fracturas).

Se recuperaron un rodado testeado de riolita y 13 núcleos. Los soportes elegidos para los núcleos fueron en su mayoría rodados $(62 \%)$ de rocas silíceas y calcedonia, aunque también se emplearon soportes indeterminables (23\%) y lascas primarias espesas (15\%). En los casos que pudo determinarse la morfología, se emplearon rodados ovalados (38\%), triangulares y chatos (12\% en ambos casos). En general, son artefactos muy espesos $(61 \%)$ y mediano pequeños $(38 \%)$. Tipológicamente pudieron identificarse cinco núcleos bipolares (38\%), dos discoidales regulares (15\%) y uno discoidal irregular $(8 \%)$. La mayoría presenta una sola plataforma de extracción $(62 \%)$, representados escasamente aquellos con dos $(23 \%)$ y múltiples plataformas $(15 \%)$. Solo en un caso se registró la preparación de los frentes. Dos artefactos se encuentran agotados y tres presentan evidencias del cambio de plataformas de extracción durante el proceso de talla.

Los desechos de talla se reparten entre 5.174 microlascas $(75,30 \%), 1.697$ lascas $(24,69 \%)$ y un hemiguijarro $(0,01 \%)$. Las materias primas mejor representadas son las rocas silíceas, las calcedonias y las calcedonias translúcidas (Tabla 4). Se registra una gran diversidad de lascas, entre las cuales aquellas indeterminables (34\%), de arista recta (21\%) y angulares (13\%) son las más frecuentes. Más de la mitad de las lascas presentan talón (55\%), con neto predominio de los filiformes (36\%). Otras variedades presentes, aunque en frecuencias menores al 6\%, son los puntiformes, lisos, lisos naturales, diedros, facetados y naturales corticales. En líneas generales predominan los desechos muy pequeños $(68 \%)$ poco espesos $(45 \%)$ y espesos $(30 \%)$.

\section{Cadenas Operativas de Producción}

A continuación se describirán las cadenas operativas de producción sobre rocas areales y extraareales. Con respecto a las primeras, se considerarán las rocas silíceas y las calcedonias, dado que son las materias primas más abundantes y presentan las secuencias de talla más completas (aquellas rocas que no superan el 3\% del conjunto muestran tendencias tecnológicas similares). El conjunto artefactual de ZA $1 \mathrm{CI}$, está compuesto mayoritariamente por microlascas y lascas muy pequeñas y espesas, pertenecientes a etapas avanzadas de confección, obtenidas por medio de la percusión blanda y/o presión. Aquellas lascas que podrían ser consideradas potenciales formas base están escasamente representadas. La variabilidad de talones representados en los soportes de los instrumentos, entre los que pueden mencionarse los filiformes, lisos, diedros y lisos naturales, indican el empleo de percusión a mano alzada blanda y dura. Durante este periodo, la talla de las rocas areales involucró la reducción in situ de rodados de diferentes morfologías y de tamaños entre 3 y $5 \mathrm{~cm}$. Se recuperaron también desechos algo mayores, en líneas generales de muy buena calidad para la talla. Aquellos rodados de morfología ovalada fueron tallados de manera bipolar con el objetivo de generar lascas largas y de espesores variables, que fueron empleadas para confeccionar raspadores, filos bifaciales, pièces esquillées e instrumentos compuestos (Figura 5). Otra manera de tallar los rodados ovalados fue mediante el débitage centrípeto, con el fin de obtener lascas cortas y anchas, de morfología redondeada, espesas a poco espesas. Estos desechos fueron seleccionados para la producción de raspadores y una punta destacada (Figura 5). La reducción de rodados rectangulares se desarrolló mediante el débitage facial (Figura 5), generando lascas espesas a muy espesas, más anchas que largas, que se emplearon para la producción de muescas y posiblemente como formas base de puntas de proyectil. Tanto este método como el bipolar fueron empleados también en la talla de rodados chatos y plaquetas. Finalmente se cuenta con escasas evidencias del débitage unipolar corto.

Con respecto a las rocas extra-areales, la cadena operativa más completa la presenta la calcedonia translúcida, a partir de la cual puede observarse el trabajo bipolar, empleando el filo natural de una de sus lascas. También se recuperó evidencia de operaciones de reducción unifacial y bifacial (lascas angulares 


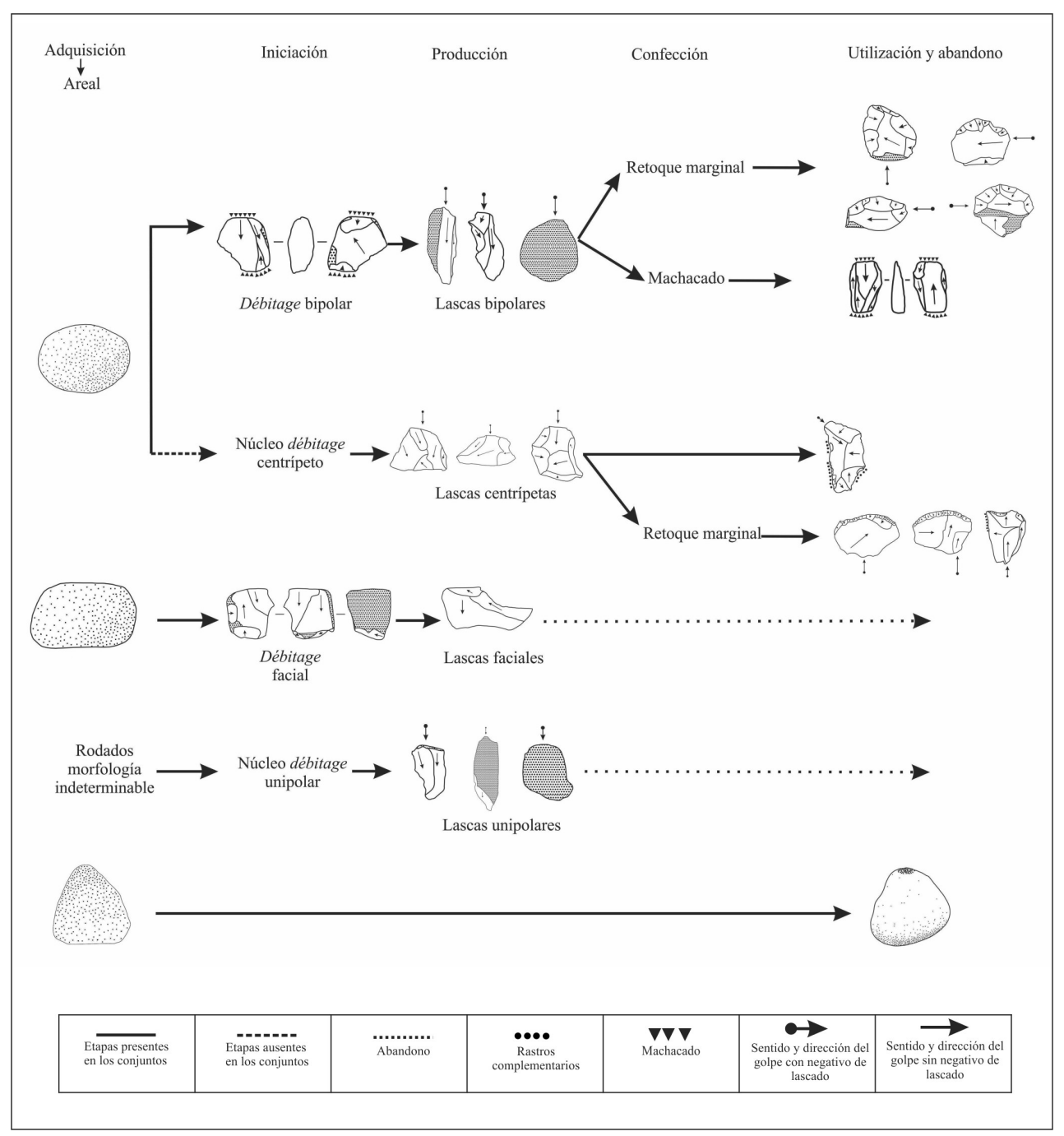

Figura 5. Cadena operativa de producción sobre materias primas areales de ZA 1 CI.

Châine opératoire on areal rocks recovered in ZA 1 CI.

sin corteza y de talones filiformes); así como de la reactivación de filos (lascas de reactivación inversa y directa). La ortocuarcita evidencia el trabajo de soportes de manera centrípeta, así como también de tareas de reducción unifacial (lascas angulares y de arista, sin corteza y de talones filiformes). Los cherts (incluídos los silíceos) y el sílice sedimentario se registran mayormente bajo la forma de desechos de etapas de formatización (lascas de arista y angulares, sin corteza, con talones filiformes y lisos), así como de escasos instrumentos (raspador y punta de proyectil). El único artefacto diagnóstico en metacuarcita es un fragmento de instrumento bifacial, mientras que por otro lado la arenisca cuarzosa se habría empleado para la confección de instrumentos de molienda.
El conjunto artefactual correspondiente a ZA 1 CS está compuesto mayoritariamente por microlascas, seguidas en mucha menor proporción por las lascas. En su mayoría son desechos de tamaños muy pequeños, poco espesos, con talones filiformes y sin evidencias de corteza. Entre estos artefactos pudieron identificarse un gran número de desechos resultantes de etapas de adelgazamiento y reducción bifacial y unifacial de soportes, así como del retoque y reactivación de filos, pero no la generación de formas base. En base a la morfología y tamaño de los talones representados, se considera que la mayoría de estas operaciones debieron involucrar la percusión directa blanda y la presión. La información que pudo obtenerse de las etapas de producción de soportes es escasa. El análisis de las 
secuencias de reducción sobre rocas areales indica el trabajo sobre diferentes morfologías de rodados, mayoritariamente de hasta $5 \mathrm{~cm}$ de longitud. La talla se llevó a cabo empleando los mismos métodos de débitage que en el periodo anterior, pero variando sus frecuencias. En este sentido, se observa una mayor selección de rodados de morfologías ovaladas, trabajados principalmente a partir del débitage bipolar y centrípeto (Figura 6). De las primeras etapas de la reducción bipolar se seleccionaron lascas utilizadas como formas base para raspadores, instrumentos compuestos, lascas con rastros complementarios y pièces esquillées, mientras que los desechos producidos en etapas avanzadas se emplearon para la confección de una preforma de punta y pièces esquillées. Con respecto a la talla centrípeta, las lascas generadas en los primeros momentos de la reducción sirvieron como soporte de una preforma de punta de proyectil, eligiendo aquellas originadas en momentos más avanzados como formas base para el desarrollo de raspadores y una lasca con retoque sumario.

En menor medida se trabajaron rodados rectangulares (Figura 6) a partir del método facial lateral, empleando las lascas originadas durante las primeras etapas para la confección de una pièce esquillée por machacado, así como de dos raspadores y una muesca por medio del retoque marginal. A medida que avanzaba la talla, se eligieron lascas como soportes de raspadores y lascas con retoque sumario. También se evidencia el empleo del débitage unipolar corto, aunque sólo está representado por un instrumento y un desecho. Con respecto a los rodados chatos y plaquetas, se observa

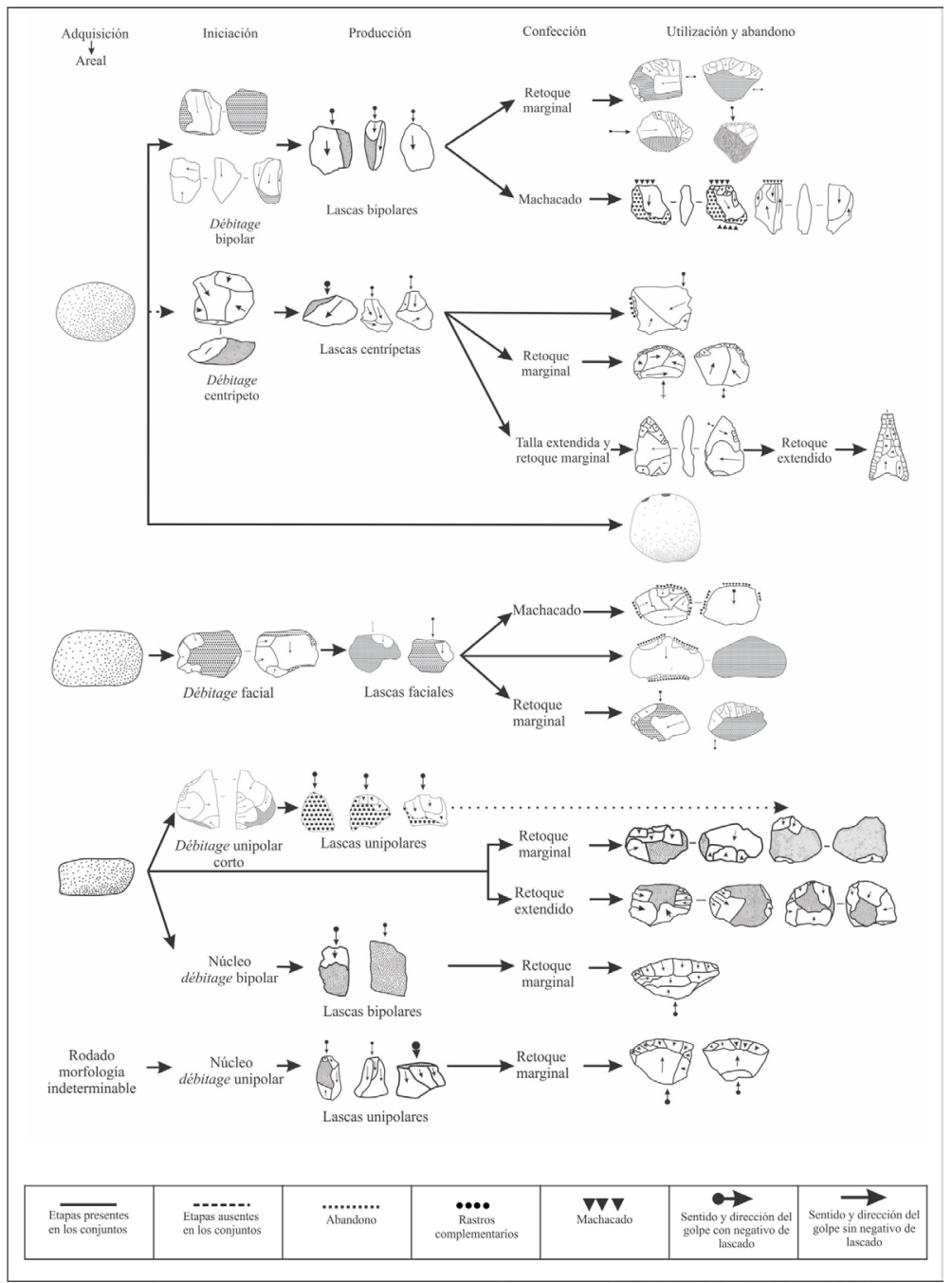

Figura 6. Cadena operativa de producción sobre materias primas areales de ZA 1 CS.

Châine opératoire on areal rocks recovered in ZA 1 CS. 
por un lado el façonnage de estos soportes a partir de la talla y retoque para la confección de esbozos bifaciales y preformas (Figura 6). Por otro lado, también se registra la fracturación bipolar de estas plaquetas y rodados (Figura 6), generando soportes para diversos instrumentos, como un raspador, un instrumento compuesto, una pieza con borde machacado y una pièce esquillée.

En relación a las rocas extra-areales, nuevamente la cadena operativa mejor representada es la de la calcedonia translúcida, cuyo registro indica el descortezamiento in situ de soportes, tanto a partir de la percusión directa (talones naturales corticales) como con apoyo (talones filiformes astillados). La talla ocurrió, al igual que para las rocas areales, principalmente mediante el débitage centrípeto y bipolar, seleccionando a partir de este último un soporte para una pièce esquillée. Sumado a ello se registra una gran cantidad de desechos de adelgazamiento y reducción bifaciales, así como de retoque, aunque escasas lascas que pudieran servir como potenciales formas base. Esta evidencia, junto con la presencia de puntas de proyectil y preformas, sugiere la producción $\mathrm{y}$ mantenimiento de instrumentos bifaciales in situ. El registro de ortocuarcita se compone de microlascas y lascas de menos de $3 \mathrm{~cm}$ de longitud, sin evidencias de corteza y de talones lisos, filiformes y puntiformes. A partir de las mismas pudo establecerse el empleo de la talla bipolar, así como también de operaciones de façonnage realizadas mediante la percusión blanda y presión. Tanto la metacuarcita (desechos poco diagnósticos, algunos de ellos con corteza), el sílice sedimentario (microlascas producto de etapas de formatización) y el chert (lascas bipolares menores a $3 \mathrm{~cm}$ y microlascas de reducción y retoque) están presentes bajo la forma de escasos desechos de talla, mientras que la limolita se registra en una pièce esquillée y la arenisca cuarzosa en un fragmento de superficie activa de molienda.

\section{Discusión}

El siguiente apartado será estructurado en función de tres ejes que permitirán sintetizar y discutir los datos expuestos anteriormente: el aprovisionamiento y uso de materias primas, la producción del instrumental y finalmente la integración de la información resultante del análisis lítico con otras líneas de evidencia analizadas en el sitio. A lo largo de los primeros dos apartados, a su vez, se compararán las tendencias tecnológicas de ambos componentes de ZA 1 con las de otros sitios del CIRC pertenecientes a cada lapso del Holoceno Tardío.

\section{Aprovisionamiento y uso de materias primas}

La explotación de rocas durante el Holoceno Tardío inicial (ZA 1 CI) se habría orientado al empleo mayoritario de rodados de rocas silíceas y calcedonias, de hasta $4 \mathrm{~cm}$ de longitud, recolectados en diferentes lugares del interior del área de estudio. En menor proporción se observa el uso de materias primas extraareales, como las ortocuarcitas de Tandilia, cherts de la Meseta del Fresco y/o Laguna El Carancho, sílice sedimentario que posiblemente provenga de los Bajos sin Salida y calcedonias translúcidas de la Meseta de Somuncurá y/o el Golfo San Matías (Figura 2). También, se registró una punta de proyectil confeccionada sobre una calcedonia gris de origen extra-areal, cuya área de aprovisionamiento aún no fue identificada. La baja frecuencia en la que se registran las rocas extra-areales, sumada a su presencia como instrumentos y lascas de las etapas de formatización y delineación de filos (i.e., adelgazamiento, reducción y retoque), permiten proponer que la obtención de estas materias primas habría resultado de intercambios con cazadores-recolectores que habitaron las subregiones Pampa Húmeda, Seca y Norpatagonia (Figura 2). El registro de metacuarcitas y areniscas cuarzosas procedentes de las sierras de Ventania resultó poco diagnóstico para inferir estrategias de aprovisionamiento.

La ocupación del Holoceno Tardío final (ZA 1 CS) muestra nuevamente la explotación mayoritaria de rocas silíceas y calcedonias, tanto areales como extraareales. Entre estas últimas sobresalen las calcedonias translúcidas, siendo la cuarta materia prima en orden de representación en el conjunto. La presencia de lascas de descortezamiento permite proponer que esta roca pudo ser obtenida bajo la forma de rodados o artefactos con remanentes de corteza, la cual fue retirada en el sitio, permitiendo la confección de instrumentos como puntas de proyectil. Si bien este conjunto muestra cadenas más completas que en el lapso anterior, se considera que su aprovisionamiento podría haber continuado a través de intercambios, aunque de carácter más fluido. Otras rocas extra-areales presentes, aunque en porcentajes mucho menores, son las ortocuarcitas de Tandilia, el chert de Meseta del Fresco y/o Laguna El Carancho y el sílice sedimentario del área de Bajos sin Salida (Figura 2). En base a las frecuencias, categorías artefactuales y etapas de las cadenas operativas representadas, se considera que estas rocas también debieron ser obtenidas a través de redes de interacción. Al igual que el conjunto de ZA 1 CI, el registro de arenisca cuarzosa, limolita y metacuarcita de Ventania por el momento no permite proponer mecanismos de aprovisionamiento claros.

La información acerca del aprovisionamiento de rocas del conjunto artefactual de ZA 1 CI avala mayoritariamente las tendencias tecnológicas delineadas a partir del análisis de otros sitios del Holoceno Tardío inicial del CIRC, como El Caldén (ca. 3000 años AP; Armentano 2012; Martínez 2017), El Puma 3 (ca. 22001500 años AP; Martínez 2017; Santos Valero 2015) y Campo Monaldi 1 y 2 (ca. 1600 años AP, Martínez 2017; Santos Valero 2017). En todos los casos se registra el uso preferencial de rocas areales, así como bajas frecuencias 
de rocas extra-areales. Sin embargo, a diferencia de estos sitios, donde predomina casi equitativamente la explotación de basalto/andesita, calcedonia y rocas silíceas, en ZA 1 CI se observa un empleo mayoritario de rocas silíceas y calcedonias. Sumado a ello, mientras que en El Caldén, El Puma 3 y Campo Monaldi 1 y 2 las rocas extra-areales con mayor representación son las rocas cuarcíticas que afloran en Tandilia y Ventania, en ZA 1 CI la calcedonia translúcida procedente de Norpatagonia es la mejor representada. Este escenario asemeja ZA 1 CI con Loma Ruiz 1, un campamento residencial ocupado entre los ca. 1900-1600 años AP (Armentano 2012). Si bien Loma Ruiz 1 pertenece cronológicamente al Holoceno Tardío inicial, solo comparte algunos rasgos tecnológicos con los sitios anteriormente mencionados. Entre las características que lo diferencian pueden nombrarse una producción planificada sobre rocas silíceas y calcedonias areales y extra-areales, así como un aumento en las frecuencias y clases artefactuales de las calcedonias translúcidas respecto de los otros conjuntos. Esto podría responder a una elección deliberada de aquellas materias primas con mejores propiedades clásticas, en detrimento del basalto/andesita que, si bien tiene una mayor abundancia en los depósitos naturales, su calidad para la talla es menor. Finalmente, otro rasgo relevante de ZA 1 CI es el registro de una punta de proyectil de calcedonia gris de procedencia extra-areal, que no había sido registrada en el área previamente.

Con respecto al Holoceno Tardío final, al igual que los conjuntos de El Tigre (ca. 900-400 años AP; Armentano 2012; Martínez 2017) y la localidad arqueológica San Antonio (ca. 1000-800 años AP; Armentano 2012; Martínez 2017), en ZA 1 CS se observa un predominio en la selección de rodados de rocas silíceas y calcedonias, obtenidas tanto en el interior del área de estudio como en regiones aledañas. La alta frecuencia en todos los conjuntos de calcedonia translúcida y las diferentes clases artefactuales representadas, sumado a la escasa presencia de rocas procedentes del Pampa Seca y Húmeda, avalan la propuesta de Armentano (2012) en relación a una disminución en el contacto con grupos situados en regiones ubicadas al norte, así como un incremento en las relaciones sociales con aquellas sociedades que habitaban el Golfo San Matías y/o la Meseta de Somuncurá (ver discusión en Martínez et al. 2017).

\section{Producción del instrumental}

Una vez recolectados los rodados areales y trasladados al sitio, se procedió a tallarlos mediante diversos métodos de débitage, como el bipolar, facial (percusión dura con apoyo en ambos casos), centrípeto y unipolar corto (percusión dura y blanda a mano alzada en ambos casos), en función de obtener soportes diferenciados (i.e., anchos o largos, de diferentes espesores), así como lascas y soportes indeterminables que también fueron empleados como núcleos. La producción durante el Holoceno Tardío inicial se orientó a la manufactura de una amplia diversidad de instrumentos, entre los que se destacan los raspadores y puntas de proyectil (Tabla 2). En líneas generales, se observa que la delineación de filos sobre soportes tallados fue la modalidad de confección preferencial para la mayoría del instrumental, destacándose los raspadores, filos en bisel asimétrico unifacial y muescas. El façonnage sobre soportes tallados (percusión blanda y presión) se registró para la confección de puntas de proyectil, esbozos bifaciales, preformas (de puntas de proyectil e instrumentos bifaciales) e instrumentos compuestos. Otras formas de producción involucraron la modificación por uso de soportes tallados y naturales, que permitieron el desarrollo de lascas con rastros complementarios, yunques y percutores, así como el empleo de técnicas de picado, abrasión y pulido para la formatización de instrumentos de molienda. Se considera que en este conjunto las piéces esquillées también serían un objetivo de producción y no el resultado del agotamiento de núcleos bipolares, dado que su confección se dio por medio de la percusión directa con apoyo de lascas y rodados chatos.

Durante el Holoceno Tardío final se observa una clara tendencia hacia la obtención de soportes centrípetos (percusión dura y blanda a mano alzada) y bipolares (percusión dura con apoyo) a partir de la talla de rodados ovalados, presentando en la mayoría de los casos cambios de plataformas de extracción y el agotamiento de algunas piezas. El débitage facial (percusión dura con apoyo) y unipolar corto (percusión dura y blanda a mano alzada) fueron empleados sólo ocasionalmente. En este momento la producción estuvo focalizada en la confección de raspadores y puntas de proyectil, lo que también se observa a partir de la elevada frecuencia de esbozos y preformas bifaciales. Al igual que en el periodo anterior, la delineación de filos sobre soportes tallados fue la modalidad más empleada para la confección de instrumentos, mientras que el façonnage sobre soportes tallados y también naturales (percusión blanda a mano alzada y presión) siguió empleándose para la manufactura de preformas, esbozos y puntas de proyectil. También se registran lascas con rastros complementarios, yunques y percutores, producto de la modificación por uso de soportes tallados y naturales respectivamente, instrumentos modificados por medio de las técnicas de picado, abrasión y pulido, así como raspadores confeccionados mediante el delineado de filos sobre soportes naturales. Nuevamente las pièces esquillées habrían sido un objetivo de producción dada su confección sobre lascas y no el resultado del agotamiento de núcleos bipolares.

En relación a la comparación de la producción instrumental llevada a cabo en ZA 1 CI y otros conjuntos del Holoceno Tardío inicial, en todos los casos se observa la confección de una amplia variabilidad de grupos tipológicos, así como el empleo de diversos soportes y 
materias primas. El empleo mayoritario de la delineación defilossobresoportestalladostambiénesunacaracterística común con estos sitios (Armentano 2012; Santos Valero 2015, 2017). El conjunto artefactual de ZA1 CS, por otro lado, permite observar tendencias tecnológicas similares a aquellas delineadas para este mismo periodo en función del análisis del sitio El Tigre y la localidad arqueológica San Antonio (Armentano 2012; Santos y Armentano 2017). Si bien los procesos de talla indican en todos los casos un empleo sistemático del débitage centrípeto, el registro de ZA 1 CS también evidencia el uso del método bipolar en frecuencias similares para la confección de gran cantidad de soportes. A su vez, este conjunto también permite observar el empleo del método unipolar corto y la producción de instrumentos a partir del façonnage sobre soportes naturales que no había sido registrada en los otros sitios de este lapso, lo que amplía el espectro de operaciones de talla consideradas para la confección de instrumentos durante el Holoceno Tardío final. Con respecto a los instrumentos, a diferencia de El Tigre y la localidad arqueológica San Antonio, en ZA 1 CS la variabilidad de grupos tipológicos se mantiene respecto de ZA 1 CI. Es destacable, sin embargo, que tanto en ZA 1 CS como en los otros dos conjuntos, predominan las puntas de proyectil y raspadores, mostrando secuencias de producción similares. En este sentido, se observa la presencia de puntas apedunculadas no solo medianas sino también pequeñas. Mientras que las primeras fueron manufacturadas a partir del trabajo bifacial (adelgazamiento y reducción) de soportes por medio de talla y retoque, las segundas debieron requerir simplemente la reducción bifacial de lascas a partir de retoques extendidos.

\section{Integración con otras líneas de evidencia}

El análisis del conjunto lítico de ZA 1 sustenta la propuesta del empleo del sitio como una base residencial reocupada en diferentes oportunidades a lo largo del Holoceno Tardío. Como se mencionó anteriormente, esto fue planteado en función de otras líneas de evidencia, tales como los análisis geomorfológicos, tafonómicos, el estudio de los comportamientos mortuorios, de subsistencia y de tecnología cerámica (Alcaráz 2017; Borges Vaz 2019; Martínez y Flensborg 2015; Martínez et al. 2014; Stoessel et al. 2016). Los resultados obtenidos del componente inferior, referible al Holoceno Tardío inicial, indican que se habrían llevado a cabo el consumo de fauna mayor y menor, la manufactura de cerámica, la confección de instrumentos óseos y la inhumación de cuerpos en los sectores altos del médano. La presencia de diferentes estadios en la reducción de rodados, desde la producción de formas base hasta momentos relacionados a la formatización de instrumentos, delineación de filos y reactivación de los mismos, indica una confección y mantenimiento in situ de una amplia variedad de instrumentos líticos. Esta diversidad de grupos tipológicos representados en ZA 1 $\mathrm{CI}$, entre los que se registran instrumentos con distintos ángulos y morfologías de filo, una bola de boleadora, instrumentos de molienda, un yunque y un percutor, sugiere un amplio espectro de actividades. A su vez, la alta frecuencia de artefactos fracturados, instrumentos agotados, escasez de núcleos y gran cantidad de desechos no aptos como formas base, indican un contexto de depositación y/o descarte de elementos vinculados a lo doméstico (Martínez et al. 2014). Esta propuesta también se observa a partir del análisis del registro de fauna menor. En este sentido, en base al alto grado de termoalteración que cubre de manera uniforme un gran porcentaje de los restos de fauna menor y la presencia de carbones asociados, Alcaráz (2017) propuso que parte de este conjunto faunístico podría ser el resultado de actividades de limpieza de fogones o del desplazamiento y concentración de materiales como consecuencia de la desactivación de un meandro.

El componente superior del sitio indica que durante el Holoceno Tardío final este lugar volvió a ser empleado como una base residencial donde se llevaron a cabo actividades de manufactura cerámica, así como el consumo intensivo de fauna mayor y menor (Borges Vaz 2019; Martínez et al. 2014; Stoessel et al. 2016). El registro lítico indica la predominancia de etapas de formatización y reactivación de filos, con una menor presencia de producción de soportes. Si bien hay una mayor presencia de raspadores y puntas de proyectiles, sigue registrándose una amplia variabilidad instrumental. La gran cantidad de materiales recuperados, entre los que se destacan instrumentos de molienda enteros, de grandes dimensiones y muy formatizados (no considerados en este análisis), indica que este espacio habría sido intensamente utilizado (Martínez et al. 2014).

\section{Conclusiones}

A partir del análisis aquí expuesto se establece que a lo largo de toda la ocupación de ZA 1 habría prevalecido un mismo conocimiento técnico de la gestión de materias primas líticas en cuanto a los mecanismos y lugares de aprovisionamiento de rocas areales y extra-areales, la selección de determinadas litologías (rocas silíceas y calcedonias), y el empleo de similares métodos de débitage y técnicas de talla para la explotación de los nódulos y confección de instrumentos. Estos datos posibilitaron también contrastar, ampliar y modificar el modelo tecnológico propuesto con anterioridad (Santos Valero 2015, 2017). En este sentido, ZA 1 CI plantea un panorama distintivo dentro del Holoceno Tardío inicial debidoal uso preferencial de rocas silíceas y calcedonias de 
procedencia areal y extra-areal, de muy buena calidad para la talla, lo cual podría responder a un mejor conocimiento de las propiedades clásticas de las rocas disponibles. A su vez, la selección de estas rocas es un patrón característico de las ocupaciones del Holoceno tardío final del CIRC, que puede observarse no solo en ZA1 CS, sino también en sitios como El Tigre y la localidad arqueológica San Antonio. Sumado a ello, en todos los sitios la confección de puntas de proyectil se da casi exclusivamente sobre estas rocas y empleando mayoritariamente soportes que solo requirieren el adelgazamiento por retoques para su formatización. Una integración más detallada de ZA 1 CI con otros sitios del Holoceno Tardío inicial permitirá reevaluar las tendencias tecnológicas de este lapso temporal y explicar la variabilidad tecnomorfológica y tecnológica observada en estos conjuntos artefactuales. Sumado a ello, deberán realizarse estudios petrográficos sobre la punta de calcedonia gris a fin de establecer su lugar de procedencia, lo cual aportará datos novedosos acerca del uso de rocas procedentes de áreas aledañas. Con respecto a ZA $1 \mathrm{CS}$, se trata del único conjunto del Holoceno Tardío final cuantitativamente comparable al sitio El Tigre, por lo que su análisis cobra relevancia para poder avanzar sobre el entendimiento de la gestión de rocas durante el Holoceno Tardío final. El análisis de ZA 1 CS posibilitó, por un lado, ampliar el conocimiento de las modalidades de producción de instrumentos (p.ej., façonnage sobre soportes no tallados). Por otro lado, la presencia de artefactos de ortocuarcita de Tandilia y de rocas de Pampa Seca permitió avanzar sobre el entendimiento de las relaciones de interacción con áreas aledañas durante este lapso.

Para concluir, se destaca el aporte de la información de la tecnología lítica para un entendimiento más integral de las actividades desarrolladas en el sitio. Las etapas de producción representadas y la presencia de una gran variabilidad instrumental (p.ej., instrumentos con diferentes filos, preformas, esbozos, filos agotados, instrumentos de molienda intensamente formatizados), permiten sustentar la propuesta de un lugar de actividades múltiples, entre las que pueden mencionarse producción, uso y mantenimiento de instrumentos líticos, el desarrollo de actividades de molienda y de confección de instrumentos para actividades caza, entre otras. A su vez, la tecnología lítica habría funcionado de manera complementaria con la tecnología cerámica y ósea, para la primera de las cuales también se propuso una confección in situ de vasijas (Borges Vaz 2019). La gran densidad de materiales recuperados y el alto grado de manipulación que presentan los restos óseos humanos asociados al Holoceno Tardío inicial sugieren que el lugar habría sido reocupado y/o intensamente ocupado durante este lapso temporal (Martínez y Flensborg 2015; Martínez et al. 2014). Finalmente la presencia de materias primas procedentes de diferentes regiones aledañas indica el acceso mediante redes de interacción de larga distancia a rocas y por lo tanto el mantenimiento de relaciones sociales con los grupos que allí habitaban.

Agradecimientos: Los trabajos de campo de Zoko Andi 1 y el análisis de estos materiales fueron posibles gracias a la financiación del PICT Nro. 242/12, así como de la beca Doctoral otorgada a la autora por el CONICET. Agradezco a la UE-INCUAPA-CONICET por el espacio físico e instrumental necesario para llevar a cabo este trabajo. A Paula Barros, Gustavo Martínez y Manuel Carrera Aizpitarte por su lectura detallada y comentarios constructivos. A los evaluadores cuyas sugerencias permitieron mejorar la estructura y contenido del manuscrito.

\section{Referencias Citadas}

Alberti, J. y M. Cardillo 2015. Primary and secondary lithic raw material sources along the western coast of San Matías Gulf (Río Negro, province, Argentina). A first approach to their spatial variability. Quaternary International 373:63-71.

Alcaráz, A. P. 2017. La Fauna Menor de Sitios Arqueológicos del Curso Inferior del Río Colorado (Provincia de Buenos Aires): Aspectos Tafonómicos y Subsistencia de Cazadores-Recolectores durante el Holoceno Medio y Tardío. Tesis para optar al grado de Doctora en Arqueología, Facultad de Ciencias Sociales, Universidad Nacional del Centro de la Provincia de Buenos Aires, Olavarría.

Armentano, G. 2012. Arqueología en el Curso Inferior del Río Colorado. Estudio Tecnológico de las Colecciones Líticas de Norpatagonia Oriental durante el Holoceno Tardio. Departamentos de Villarino y Patagones, Provincia de Buenos Aires. Argentina. Tesis para optar al grado de Doctora en Arqueología, Facultad de Ciencias Sociales, Universidad Nacional del Centro de la Provincia de Buenos Aires, Olavarría, en co-tutela internacional con la Université de Paris Ouest-Nanterre La Défense, Paris.

Armentano, G., G. Martínez y C. Landini 2013. El sitio Loma Ruiz 1: Estrategias tecnológicas líticas durante el Holoceno Tardío
Inicial en la transicion Pampano-Patagónica oriental. Revista del Museo de Antropología 6:21-40.

Aschero, C.A. 1975. Ensayo para una clasificación morfológica de artefactos líticos aplicada a estudios tipológicos comparativos. Informe Técnico en posesión de CONICET, Buenos Aires.

Aschero, C.A. 1983. Ensayo para una clasificación morfológica de artefactos líticos aplicada a estudios tipológicos comparativos: Apéndice A-C. Cátedra de Ergología y Tecnología. Facultad de Filosofía y Letras, Universidad de Buenos Aires, Buenos Aires.

Aschero, C. A. y S. Hocsman 2004. Revisando cuestiones tipológicas en torno a la clasificación de artefactos bifaciales. En Temas de Arqueología, Análisis Lítico, compilado por A. Acosta, D. Loponte y M. Ramos, pp. 7-25. Universidad Nacional de Luján, Luján.

Babot, M.P. 2004. Tecnología y Utilización de Artefactos de Molienda en el Noroeste Prehispánico. Tesis para optar al grado de Doctora en Arqueología, Facultad de Ciencias Naturales e Instituto Miguel Lillo, Universidad Nacional de Tucumán, Tucumán.

Bayón, C., N. Flegenheimer, M. Valente y A. Pupio 1999. Dime cómo eres y te diré de dónde vienes: procedencia de rocas 
cuarcíticas en la región Pampeana. Relaciones de la Sociedad Argentina de Antropología XXIV:187-232.

Bayón, C., A. Pupio, R. Vecchi y C. Scabuzzo 2010. Localidad arqueológica Paso Mayor: nuevos estudios 40 años después. Intersecciones en Antropología 11:115-128.

Berón, M. 2004. Dinámica Poblacional y Estrategias de Subsistencia de Poblaciones Prehispánicas de la Cuenca del AtuelSalado-Chadileuvú-Curacó, Provincia de la Pampa. Tesis para optar al grado de Doctora en Arqueología, Facultad de Filosofía y Letras, Universidad de Buenos Aires, Buenos Aires.

Berón, M., I. Baffi, R. Molinari, C. Aranda, L. Luna y A. Cimino 2002. El Chenque de Lihue Calel. Una estructura funeraria en las "Sierras de la vida”. En Del Mar a los Salitrales. 10.000 de Historia Pampeana en el Umbral del Tercer Milenio, editado por D.L Mazzanti, M. Berón y F.W. Oliva, pp. 87-106. Laboratorio de Arqueología, Facultad de Humanidades, Universidad Nacional de Mar del Plata, Mar del Plata.

Boëda, E. 2000. Les techniques des hommes de la préhistoire pour interroger le présent. En Médiation Technique et Cognition: Cognition Située, Individuelle et Collective, organizado por C. Brassac, Y. Gueniffey, S. Lahlou y C. Lenay, pp.1-31. Association pour la Recherche Cognitive, Septieme École d'Été, Bonas.

Borges Vaz, E. 2019. Modos de Hacer y Representar: las Prácticas Alfareras en el Curso Inferior del Río Colorado, durante el Holoceno Tardío. Tesis para optar al grado de Doctora en Arqueología, Facultad de Ciencias Sociales, Universidad Nacional del Centro de la Provincia de Buenos Aires, Olavarría.

Carrera Aizpitarte, M. 2014. Estudio de las Estrategias de Aprovisionamiento Lítico en las Áreas Curacó, Bajos sin Salida, Valles Transversales y Centro-Este (Provincia de La Pampa, Argentina). Tesis para optar al grado de Doctor en Arqueología, Facultad de Ciencias Sociales, Universidad Nacional del Centro de la Provincia de Buenos Aires, Olavarría.

Colombo, M. 2011. El área de abastecimiento de las ortocuarcitas del grupo Sierras Bayas y las posibles técnicas para su obtención entre los cazadores y recolectores pampeanos. Intersecciones en Antropología 12:231-244.

Flegenheimer, N., S. Kain, M. Zárate y A. Barna 1996. Aprovisionamiento de cuarcitas en Tandilia, las canteras del arroyo Diamante. Arqueología 6:117-141.

Flensborg, G. 2017. Análisis tecnomorfológico de adornos, cuentas y ornamentos. En Arqueología de Cazadores-Recolectores del Curso Inferior del Río Colorado (Provincia de Buenos Aires, Argentina) Aportes al Conocimiento de las Ocupaciones Humanas PampeanoPatagónicas, editado por G. Martínez, pp. 230-329. Instituto de Investigaciones Arqueológicas y Paleontológicas del Cuaternario Pampeano-Consejo Nacional de Investigaciones Científicas y Técnicas-Universidad Nacional del Centro de la Provincia de Buenos Aires, Olavarría

Hermo, D. y E. Terranova 2016. Distribución de núcleos en el sector central de la Meseta de Somuncurá(Río Negro,Argentina). Relaciones entre la base regional de recursos líticos y el aprovisionamiento de materias primas líticas. Arqueología 22 (2):291-310.

Inizan, M.L., M. Reduron-Ballinger, H. Roche y J. Tixier 1995 Technologie de la Pierre Taillée. Centre Nationale de la Recherche Scientifique y Université de Paris X Nanterre, Meudon.

Leroi-Gourhan, A. 1971 [1964]. El Gesto y la Palabra. I: Técnicas y Lenguaje. Traducido por F. Carrera. Ediciones de la BibliotecaUniversidad Central de Venezuela, Caracas.

Marchand, G. 1999. La Néolithisation de l'Ouest de la France: Caractérisation des Industries Lithiques. British Archaeological Reports. International Series 748, Oxford.
Martínez, G. 2017. Arqueología de Cazadores-Recolectores del Curso Inferior del Río Colorado (Provincia de Buenos Aires, Argentina). Aportes al Conocimiento de las Ocupaciones Humanas Pampeano-Patagónicas. Instituto de Investigaciones Arqueológicas y Paleontológicas del Cuaternario Pampeano-Consejo Nacional de Investigaciones Científicas y Técnicas-Universidad Nacional del Centro de la Provincia de Buenos Aires, Olavarría.

Martínez, G. y G. Flensborg 2015. New evidences of human corpse manipulation among hunter-gatherers societies in Northeastern Patagonia (Argentina). Abstracts of the SAA $80^{\text {th }}$ Annиal Meeting, pp. 654. San Francisco.

Martínez, G. y F. Santos Valero 2020. Petrographic thin sections and exotic rocks provenience among hunter-gatherers societies in the eastern Pampa-Patagonia transition (lower basin of the Colorado river, Argentina). Archaeometry 62 (3): 493-505.

Martínez, G., G.A. Martínez, L. Stoessel, A.P. Alcaráz, F. Santos Valero, G. Flensborg, P. Bayala y J.F. Onorato 2014. Resultados preliminares del sitio Zoko Andi 1. Aportes para la arqueología del curso inferior del río Colorado (Provincia de Buenos Aires). Revista del Museo de Antropología 7 (1):105-114.

Pelegrin, J. 1995. Technologie Litihique: Le Châtelperronien de Roc-de-Combe (Lot) et de La Côte (Dordogne). Centre Nationale de la Recherche Scientifique, Paris.

Santos Valero, F. 2015. Contribuciones al conocimiento de la tecnología lítica en el valle inferior del río Colorado: sitio El Puma 3. Intersecciones en Antropología 16:237-251.

Santos Valero, F. 2017. La Gestión de Rocas a través del Tiempo: Aportes al Estudio de la Tecnología Lítica durante el Holoceno Medio y Tardío en el Valle Inferior del Río Colorado (Provincia de Buenos Aires). Tesis para optar al grado de Doctora en Arqueología, Facultad de Ciencias Sociales, Universidad Nacional del Centro de la Provincia de Buenos Aires, Olavarría.

Santos Valero, F. y G. Armentano 2017. La tecnología lítica. En Arqueología de Cazadores-Recolectores del Curso Inferior del Río Colorado (Provincia de Buenos Aires, Argentina). Aportes al Conocimiento de las Ocupaciones Humanas PampeanoPatagónicas, editado por G. Martínez, pp. 121-145. Instituto de Investigaciones Arqueológicas y Paleontológicas del Cuaternario Pampeano-Consejo Nacional de Investigaciones Científicas y Técnicas-Universidad Nacional del Centro de la Provincia de Buenos Aires, Olavarría.

Santos Valero, F. y G. Martínez 2019. Strategies for quartzitic raw materials procurement in the eastern Pampa-Patagonia transition of Argentina during the Initial late Holocene. Lithic technology 44 (2):55-73

Stoessel, L., A.P. Alcaráz y G. Martínez 2016. Nuevas tendencias acerca de la explotación de recursos faunísticos durante el Holoceno tardío en el área de transición pampeano-patagónica oriental: la evidencia del sitio Zoko Andi 1. En IV Congreso Nacional de Zooarqueología Argentina. Libro de Resúmenes, compilado por M. Salemme, F. Santiago, A. Tivoli, M. Vázquez y A.F. Zangrando, pp. 78. Universidad Nacional de Tierra del Fuego, Ushuaia.

Stoessel, L., F. Santos Valero y G. Martínez 2020. Primeros resultados del estudio de la tecnología ósea durante el Holoceno tardío en el curso inferior del río Colorado (transición pampeano-patagónica oriental, provincia de Buenos Aires). Intersecciones en Antropología $21(2): 159-172$

Tixier, J. 1963. Typologie de l'Épipaléolithique du Maghreb. Centre de Recherches Anthropologiques Préhistoriques et Ethnographiques, Paris.

Turq, A. 2000. Technologie lithique. Paléo (suppl.) 26-32. 


\section{Notas}

${ }^{1}$ Se consideran pièces esquillées a aquellos artefactos "generalmente rectangulares o cuadrados, casi siempre de muy pequeñas dimensiones, que presentan en sus dos extremidades (rara vez una sola) melladuras frecuentemente bifaciales, causadas por una percusión violenta" (Tixier 1963:146, traducción de la autora). Se caracterizan por poseer una zona con pequeños lascados, de extensión corta y morfología escamosa, así como una zona de lascados largos, con ondas de percusión bien marcadas, resultando a menudo en piezas bifaciales (Tixier 1963).

${ }^{2} \mathrm{El}$ término bâtonnet hace referencia a desechos de sección triangular o cuadrangular que no presentan talón y resultan de la fractura de pièces esquillées (Tixier 1963). 
